\title{
ASPECTOS DE ENFERMAGEM, NUTRIÇÃO, FISIOTERAPIA E SERVIÇO SOCIAL NO TRANSPLANTE DE MEDULA ÓSSEA
}

\author{
NURSING, NUTRITION, PHYSICAL THERAPY AND \\ SOCIAL WORK ASPECTS OF BONE MARROW TRANSPLANTATION
}

Jane C. Anders ${ }^{1,3}$; Virtude M. Soler ${ }^{1,2}$; Edith M. Brandão ${ }^{4}$; Elisa C. Vendramini5; Clara LS Bertagnolli6;

Pedro G. Giovani ${ }^{1}$; Emília C. Carvalho ${ }^{7}$; Vivian M.M. Suen ${ }^{8}$; Júlio S. Marchini ${ }^{9}$ \& Júlio C. Voltarelli ${ }^{9}$

\begin{abstract}
'Enfermeiro da Unidade de Transplante de Medula Óssea do Hospital das Cínicas da Faculdade de Medicina de Ribeirão Preto da Universidade de São Paulo (HCFMRPUSP), ${ }^{2}$ Mestranda, Escola de Enfermagem de Ribeirão Preto da Universidade de São Paulo (EERPUSP), ${ }^{3}$ Doutoranda da EERP-USP; ${ }^{4}$ Nutricionista da Unidade de TMO do HCFMRP-USP, ${ }^{5}$ Fisioterapeuta da Unidade de TMO do HCFMRPUSP, ${ }^{6}$ Assistente Social da Unidade de TMO do HCFMRP-USP, ${ }^{7}$ Docente do Departamento de Enfermagem Geral e Especializada da EERP-USP, ${ }^{8}$ Médica Assistente da Divisão de Nutrologia do HCFMRP-USP, ${ }^{9}$ Docente do Departamento de Clínica Médica da FMRP-USP. Correspondência: Prof. Dr. Júlio C. Voltarelli, Departamento de Clínica Médica, Hospital das Clínicas, Campus USP, 14048-900 Ribeirão Preto-SP, E-mail: jcvoltar@fmrp.usp.br
\end{abstract}

ANDERS JC; SOLER VM; BRANDÃO EM; VENDRAMINI EC; BERTAGNOLLI CLS; GIOVANI PG; CARVALHO EC; SUEN VM; MARCHINI JS. \& VOLTARELLI JC. Aspectos de enfermagem, nutrição, fisioterapia e serviço social no transplante de medula óssea. Medicina, Ribeirão Preto, 33: 463-485, out./dez. 2000.

RESUMO: O sucesso do transplante de medula óssea (TMO) depende da ação entrosada de uma variedade de profissionais, além da equipe médica, para atender às múltiplas e complexas necessidades dos pacientes submetidos ao TMO. Nesta revisão, discute-se a atuação das equipes de enfermagem, nutrição, fisioterapia e assistência social na assistência desses pacientes. O papel dos profissionais de saúde mental (psicólogos e psiquiatras) foi tratado em um capítulo separado deste Simpósio.

UNITERMOS: Transplante de Medula Óssea. Transplante de Células Hematopoéticas Primitivas. Enfermagem. Cateterismo Venoso Central. Mucosite. Nutrição. Doença Enxerto-Contra-Hospedeiro. Fisioterapia. Reabilitação. Serviço Social.

\section{INTRODUÇÃO}

No transcorrer dos anos, o transplante de medula óssea (TMO) tornou-se uma modalidade terapêutica utilizada de uma maneira crescente em muitas doenças na idade adulta e na infância. Apesar de ser um tratamento dispendioso, complexo e associado a alta morbimortalidade, o TMO é uma das modalidades terapêuticas mais importantes da Oncologia, pois consegue curar ou prolongar significativamente a sobrevida de um grande número de pacientes refratários a outros tipos de tratamento. Doenças não-neoplá- sicas, como a anemia aplástica e as imunodeficiências e, mais recentemente, as hemoglobinopatias e as enfermidades auto-imunes também têm sido tratadas com sucesso pelo TMO.

O TMO é um procedimento terapêutico que consiste na infusão, por via intravenosa, de sangue da medula óssea, obtido de doador previamente selecionado, em receptor adequadamente condicionado, isto é, submetido a um regime preparativo qumioterápico, com ou sem radioterapia, com propriedades mielo e imunoablativas. A finalidade do TMO é reconstruir o órgão hematopoético enfermo, lesado por um meca- 
nismo auto-imune, tóxico ou em decorrência de proliferação celular neoplásica ou reacional ${ }^{(1)}$. Também tem indicação nas doenças neoplásicas que não afetam primariamente a medula óssea, como os linfomas e os tumores sólidos, em que a dose de quimioterapia ou radioterapia necessária para o tratamento pode comprometer o sistema hematopoético de maneira irreversível. Desta forma, o transplante de medula óssea pode ser utilizado nos tratamento de uma variedade de doenças hematológicas, imunológicas, oncohematológicas e oncológicas.

As primeiras experiências com TMO alogênico (entre indivíduos diferentes da mesma espécie) ocorreram no século XIX, mas elas só tiveram sucesso no final da década de 60 do século XX, com a descoberta do principal sistema de histocompatibilidade humano, composto de antígenos HLA (human leukocyte antigens) e com o trabalho pioneiro do $\mathrm{Dr}$ E.D. Thomas em Seattle, o que lhe valeu o Prêmio Nobel de Medicina em $1990^{(2,3)}$. A partir daí, muitos avanços no campo do TMO têm levado ao aperfeiçoamento de técnicas de diagnóstico e tratamento relacionadas ao procedimento, produzindo um aumento considerável nas taxas de sobrevida dos pacientes submetidos ao TMO alogênico. Entretanto, complicações importantes, de natureza infecciosa, imunológica (rejeição e, principalmente, doença do enxerto-contra-hospedeiro) e tóxica, decorrente do condicionamento, limitam consideravelmente a aplicação deste tipo de transplante.

O desenvolvimento da tecnologia de estimulação e congelamento da medula óssea possibilitou que o TMO autólogo e, posteriormente, o transplante autólogo de células tronco hematopoéticas mobilizadas para o sangue periférico se tornassem cada vez mais importantes no tratamento de uma série de tumores sólidos e neoplasias linfohematopoéticas. O transplante autólogo tem morbimortalidade precoce muito inferior ao alogênico, pela ausência de complicações imunológicas decorrentes de alorreatividade, mas sua principal limitação é a alta incidência de recidiva da doença básica. Atualmente, há uma variedade de opções de transplantes, em termos de fontes celulares e tipos de doadores (vide Capítulo VII deste Simpósio).

No Brasil, o início do TMO se deu no Hospital das Clínicas da Universidade Federal do Paraná, em 1979, tendo realizado seu milésimo transplante em $1998^{(4)}$. Em 1983, no Rio de Janeiro, uma outra unidade foi inaugurada no Instituto Nacional do Câncer ${ }^{(5)} \mathrm{e}$ em 1988, teve início o programa de TMO na Faculdade de Medicina da Universidade de São Paulo em São Paulo $^{(6)}$. O primeiro programa do interior do país foi inaugurado no Hospital das Clínicas da Faculdade de Medicina de Ribeirão Preto da Universidade de São Paulo (HCFMRP-USP), em 1992, seguido pela Universidade de Campinas (UNICAMP) em 1993. Atualmente, há no país cerca de 16 Unidades de TMO credenciadas pelo Sistema Único de Saúde (SUS), ao lado de um menor número de Unidades privadas, que realizam aproximadamente 800 transplantes/ano. Este número, entretanto, está muito aquém das necessidades do país, pois ele também mede o tamanho da fila de espera. Nas regiões Norte e Nordeste do país, por exemplo, não há qualquer Unidade de TMO credenciada pelo SUS e só recentemente iniciaram suas atividades unidades privadas em Salvador e Recife. Assim, um grande número de pacientes carentes transplantados nas Unidades de TMO do Sul e do Sudeste provêem de outros estados, o que agrava sobremaneira os problemas sócio-econômicos envolvidos.

A agressividade do TMO acarreta um estado de comprometimento múltiplo de órgãos e tecidos que inclui profunda depressão imunológica, em decorrência dos efeitos colaterais da quimioterapia/radioterapia, levando a grande predisposição a infecções e outras complicações graves. O paciente submetido a este tratamento necessita de assistência e cuidados intensivos de uma equipe multiprofissional que deverá ajudálo em todas as fases do tratamento (pré-TMO, aspiração, processamento e infusão da medula óssea, pósTMO precoce e tardio). Profissionais de diversas especialidades procuram trabalhar juntos, cada um levando sua contribuição específica para propiciar ao paciente uma recuperação integral, ou próxima dela, ao final do procedimento. Nesta revisão, será discutido o papel das equipes de enfermagem, nutrição, fisioterapia e assistência social na assistência ao paciente submetido ao TMO. A contribuição da equipe de saúde mental (psicologia e psiquiatria) foi extensivamente discutida no Capítulo VI deste Simpósio.

\section{ASSISTÊNCIA DE ENFERMAGEM NO TMO}

A equipe de enfermagem vem conquistando, dia a dia, um espaço cada vez maior na assistência ao paciente submetido ao TMO, exigindo-se do enfermeiro, no desempenho de suas funções, a elaboração de um 
plano terapêutico detalhado e sistematizado, utilizando elementos da literatura específica em TMO e da metodologia científica. Tendo em conta a gravidade do comprometimento orgânico do paciente transplantado e o caráter crítico e instável de suas condições físicas e emocionais, o enfermeiro que atua nesta área deve ter conhecimentos específicos aprofundados, uma vez que atuará de forma decisiva em todas as fases do tratamento.

$\mathrm{O}$ atendimento das necessidades específicas dos pacientes submetidos ao TMO se completa pela presença do enfermeiro a seu lado, que é a mais extensa e estreita entre a de todos os profissionais envolvidos. O suporte emocional proporcionado pelo enfermeiro valoriza e enriquece a assistência, favorecendo o aprendizado do paciente e de seus familiares no desenvolvimento de autocuidados e da educação sanitária e no fortalecimento da personalidade do paciente, que é essencial para o sucesso do tratamento. Neste sentido, o trabalho de Carvalho et al. $(2000)^{(6 a)}$ analisou, através de entrevistas estruturadas, o atendimento das necessidades interpessoais (de inclusão, controle e afeição) dos pacientes pela equipe de enfermagem nas várias fases do TMO.

O exercício do profissional enfermeiro em uma unidade de TMO abrange um amplo campo de atuação. Ao mesmo tempo que o enfermeiro tem a responsabilidade pelo planejamento, execução, coordenação, supervisão e avaliação da assistência de enfermagem em TMO, em todas as fases do tratamento e nos níveis hospitalar, ambulatorial e domiciliar, ele também tem a responsabilidade da educação e orientação dos pacientes e de seus familiares.

A literatura aponta para a necessidade de se oferecer cuidados específicos aos pacientes submetidos ao TMO, no sentido de, além de assisti-lo nos aspectos bio-psico-sócio-espirituais, concorrer para minimizar os efeitos colaterais decorrentes do tratamento. Levantamento de problemas e adoção de soluções adequadas e intervenções necessárias para atingir esses objetivos, com ênfase na otimização dos autocuidados, fazem parte do panorama de ações do enfermeiro $^{(7)}$. O tratamento da mucosite, os cuidados com a pele e com o catéter venoso central e com os procedimentos do isolamento protetor incluem-se entre as principais áreas específicas de atuação da enfermagem no TMO.

Nesta revisão, serão tratados dois aspectos particulares da assistência de enfermagem no TMO: os cuidados com o catéter venoso central e com a mucosite.

\subsection{Catéter de Longa Permanência - Cuidados de Enfermagem}

O uso do catéter venoso central no paciente submetido ao TMO é de grande importância para permitir cuidados intensivos decorrentes da terapêutica, tais como: administração de grande quantidade de drogas e fluidos, de nutrição parenteral total e de hemoderivados, coleta repetida de exames e monitorização de pressão venosa central ${ }^{(8,9,10)}$. Segundo Toyonaga et al. ${ }^{(8)}$, sua escolha se deve às vantagens que oferece: facilidade de manuseio e manutenção, longa permanência, conforto e baixo risco de complicações.

Os catéteres semi-implantados de longa permanência são de borracha siliconizada, flexível, radiopacos, têm paredes espessas e os modelos podem ser de uma via dupla ou tripla vias. Todos têm um manguito de dracon, que fica cerca de $5 \mathrm{~cm}$ acima (proximal) do ponto de saída, cuja finalidade é fixá-lo através de um processo fibrose em torno do manguito, impedindo sua movimentação e diminuindo o risco de infecção bacteriana ascendente. De modo geral, o ponto de saída destes cateteres localiza-se na região acima do mamilo, de onde, por penetração da pele, segue então por um túnel subcutâneo até a veia desejada (a cefálica, jugular interna ou subclávia). Este catéter pode ser introduzido na veia safena até a cava inferior, exteriorizando-se na região hiogástrica ou inguinal.

A cicatrização dos cateteres semi-implantáveis ocorre entre 2 a 4 semanas, podendo permanecer in loco durante varias semanas e ate meses. A sua retirada é fácil, por simples tração.

\subsubsection{Implante do catéter de longa perma- nência}

A implantação do catéter é realizada pela equipe médica, através de dissecção da veia jugular externa, jugular interna ou cefálica. Utiliza-se técnica asséptica cirúrgica rigorosa, sob anestesia local em adultos e anestesia geral em crianças com idade inferior a 12 anos. A veia selecionada depende do calibre do catéter indicado para cada paciente. Isolada a veia, é aberto um túnel subcutâneo usando-se um trocáter a partir da primeira incisão (na entrada do catéter) até um local no tórax ao nível do quarto e quinto espaços intercostais, na linha hemiclavicular, onde a segunda incisão (orifício de saída do catéter) foi feita. $\mathrm{O}$ anel de drácon é posicionado no túnel subcutâneo, entre as duas incisões, sobre um espaço intercostal. O catéter é inserido e posicionado na entrada do átrio direito e 
se faz a sutura da incisão no orifício de saída do túnel do catéter, com um ponto único, com o objetivo de fixar o catéter até a completa fibrose do anel de dracron no tecido subcutâneo ${ }^{(9)}$. Para controle da posição do catéter, utiliza-se a radioscopia.

\subsubsection{Cuidados com o catéter}

Segundo Bonassa $(1992)^{(10)}$, são três os principais cuidados com o catéter de longa ressonância: o curativo, a heparinização e a troca da tampa. Na nossa Unidade, adotamos o seguinte esquema para cada um desses cuidados:

\subsubsection{Curativo}

O curativo é realizado pelo enfermeiro, diariamente após o banho ou mais freqüentemente, caso seja necessário. Nos primeiros três dias após o implante do catéter, orientamos ocluir o local durante o banho. Utilizamos para assepsia a Clorexidina alcoólico (Riohex ou Chlorohex) embebida em gaze estéril, aplicando-a ao redor da inserção do catéter, através de movimentos circulares, repetindo três vezes, trocando a gaze a cada vez. A água oxigenada só é utilizada caso haja presença de sangue. Após o procedimento, o local é ocluído com gaze estéril fazendose a fixação com esparadrapo ou micropore. Os pontos devem ser retirados pelo enfermeiro, a partir do sétimo dia de colocação do catéter.

No caso de alta da unidade de transplante, orientamos o paciente e a sua família a higienizar o local do catéter com sabonete neutro durante o banho diário. Nos retornos ambulatoriais realizamos o curativo conforme a técnica descrita acima.

Os frascos (amotolias) e as soluções utilizadas para o curativo do catéter sáo trocados semanalmente.

\subsubsection{Heparinização}

Na heparinização das vias do catéter, utilizamos $3 \mathrm{ml}$ de solução de heparina, contendo 300 unidades, em cada via. Caso o catéter não esteja sendo utilizado, devemos trocar a heparina a cada 7 dias. $\mathrm{O}$ paciente e/ou familiares não devem realizar esse procedimento em casa.

\subsubsection{Sistema Inter-Link}

No nosso serviço, utilizamos um sistema chamado "Inter-link" com conector "Luer-lock" a fim de diminuir o risco de infecção no catéter. Com essa padronização, mantemos o manuseio do catéter em um sistema fechado, sendo trocado todo o sistema e os equipos de soros a cada 72 horas, sendo apenas os equipos de Nutrição Parenteral Total (NPT) trocados a cada 12 horas.

\subsubsection{Técnica de coleta de sangue}

A coleta de sangue pelo catéter para exames de rotina é realizada do seguinte modo :

- Aspirar e desprezar $5 \mathrm{ml}$ de sangue em adultos e $3 \mathrm{ml} \mathrm{em} \mathrm{crianças.} \mathrm{Em} \mathrm{seguida,} \mathrm{coletar} \mathrm{a} \mathrm{quanti-}$ dade necessária de acordo com o exame;

- Coletar sangue sempre da via que esteja heparinizada;

No caso de estar havendo infusão de soro, medicações, hemoderivados e NPT (Nutrição Parenteral Total), interromper a infusão fechando a via do catéter, lavar com solução salina isotônica ou água destilada (20 $\mathrm{ml}$ em adultos e $10 \mathrm{ml}$ em crianças). Aguardar um minuto, aspirar e desprezar $5 \mathrm{ml}$ de sangue em adulto e $3 \mathrm{ml}$ em crianças, coletar a quantidade necessária para realização do exame e retornar a infusão interrompida.

\subsubsection{Complicações dos catéteres de longa per- manência}

A implantação e utilização de catéteres de longa permanência envolvem riscos de complicações normalmente associados com a punção venosa central, falhas mecânicas e infecções, sendo as mais comuns: fratura, obstrução e deslocamento do catéter, extravazamento de medicamentos, hematomas, embolia gasosa, pneumotórax, hemotórax, hidrotórax, perfuração ou laceração de vasos ou vísceras, tamponamento cardíaco, arritmia cardíaca, lesão do plexo braquial, intolerância ao catéter, trombose venosa, inflamação e necrose da pele ${ }^{(8 / 12)}$ (Tabela I).

Tabela I - Principais complicações dos catéteres venosos de longa permanência

Infecção do sítio externo

Infeção do túnel (tunelite)

Fratura, obstrução e deslocamento do catéter

Extravazamento de medicamentos

Pneumotórax, hemotórax, hidrotórax

Trombose venosa

Hematoma

Inflamação ou necrose da pele

Arritmia cardíaca 
Dentre as complicações, a mais importante e que pode ser limitante do uso do catéter, é a infecção. Ela ocorre predominantemente no sítio externo, com a presença de eritema, edema, induração de até $2 \mathrm{~cm}$ do sítio de inserção ou secreção purulenta, ou no túnel com eritema, edema e induração ao longo do trajeto subcutâneo, atingindo mais de $3 \mathrm{~cm}$ do sítio de inserção do cateter ${ }^{(11)}$.

Assim, há necessidade de obedecer, rigorosamente, os princípios gerais de assepsia no manuseio do catéter contribuindo também para o controle de infecções. Essas medidas devem ser tomadas de uma forma conjunta, num complexo de atividades fundamentadas em instalações adequadas e executadas dentro de rigorosa técnica asséptica. A desobediência a uma das técnicas, como por exemplo, na lavagem das mãos, pode levar à transmissão de infecção, mesmo diante de todo avanço tecnológico. A conscientização e a educação continuada da equipe de saúde, quanto à importância do manuseio adequado do catéter, seguindo uma padronização de rotinas, são fatores que diminuem o risco de complicações, proporcionando uma assistência com qualidade ao paciente.

\subsection{Assistência de enfermagem a mucosite}

\subsubsection{Considerações gerais sobre mucosite pós-TMO}

Em decorrência do regime de condicionamento mieloablativo, onde são utilizados agentes quimioterápicos ou radioterápicos bastante agressivos, a maioria dos pacientes submetidos ao TMO tem, como uma das suas complicações iniciais mais comuns, o aparecimento de mucosite. Outras complicações orais póstransplante incluem sangramentos, infecções, xerostomia e perda do paladar, que interferem significativamente na alimentação, no bem-estar e na auto-imagem do paciente ${ }^{(13)}$.

Segundo Sandow \& Baughman (1994) ${ }^{(14)}$, mucosite é um termo geral para descrever um estado de irritação da mucosa oral que inclui eritema, inflamação, ulceração e infecção. Já segundo Rodriguez $(2000)^{(15)}$, mucosite é uma inflamação que pode ocorrer em qualquer parte da mucosa de revestimento do trato gastrointestinal, desde a boca até o ânus. As lesões predominam na mucosa jugal, em que a capacidade de renovação das células epiteliais está mais comprometida. Outras mucosas de revestimento, como as do trato respiratório e gênito-urinário, podem também ser envolvidas, em situações muito especiais.
A mucosite começa por volta do período em que a terapia condicionante foi completada, piora gradativamente, atingindo uma intensidade máxima na segunda semana pós-transplante, declinando gradativamente até que se resolva completamente, coincidindo com o enxertamento. Assim, o início e a duração da mucosite correlacionam-se com o curso da neutropenia e podem ser influenciados pela capacidade de metabolizar medicamentos quimioterápicos com potencial estomatotóxico, como o metotrexate. O uso de ácido folínico após o metotrexate pode reduzir sua toxicidade e a gravidade da mucosite.

O modelo patobiológico da mucosite foi proposto por Sonis em $1988^{(16)}$, na tentativa de resumir o conhecimento atual acerca da injúria nas barreiras mucosas (mucosal barrier injury, MBI) oral e gastrointestinal. Este modelo descreve quatro sucessivas fases do processo: a fase inflamatória, que ocorre logo em seguida ao condicionamento (fase 1), seguida do comprometimento epitelial, 4 a 5 dias após (fase 2), evoluindo para ulceração e proliferação microbiana, geralmente na $2^{\mathrm{a}}$ semana após a agressão, coincidindo com o pico da neutropenia (fase 3 ) e resolvendose com cicatrização, caracterizada por renovação epitelial, recuperação da contagem de leucócitos e reestabelecimento da flora microbiana local (fase 4).

Alguns fatores pré-existentes comuns estão associados ao aumento do risco de complicações orais após o condicionamento, como doenças orais prévias, incluindo periodontite, higiene oral ineficaz, restaurações defeituosas, próteses instáveis, presença de dispositivos ortodônticos ou outras fontes de irritação da mucosa, como drogas e alimentos irritantes ${ }^{(15)}$.

Infecções orais desempenham um importante papel na evolução da mucosite e estão intimamente associadas ao processo. Podem acometer os dentes, a gengiva e a mucosa e ter etiologia bacteriana, viral ou fúngica. Infecções bacterianas de partes moles podem afetar qualquer parte da boca, sendo frequentes as gengivites nos pacientes com periodondite préexistente e a infecção da mucosa bucal secundária à desintegração e ulceração. Segundo Sonis ${ }^{(16)}$, essas infecções devem sempre ser consideradas mistas, por gram-positivos e gram-negativos, incluindo anaeróbios. Usualmente aparecem perfurações profundas na mucosa, com áreas necróticas, levando o paciente a sentir grande desconforto. As glândulas salivares, principalmente as parótidas, podem ser infectadas (por estafilococos ou estreptococos) em decorrência da estase salivar. Boa hidratação e estímulo da secreção 
salivar com pedras de gelo, picolés e pastilhas de limão sem açúcar podem prevenir estas infecções.

As infecções fúngicas orais mais comuns pósTMO são causadas por Candida albicans, produzindo placas brancas elevadas em qualquer parte da boca, podendo disseminar para o esôfago, causando disfagia, para os pulmões, causando pneumonite ou para a corrente sanguínea. Infecções virais por Herpes simplex são bastante comuns na cavidade oral, surgindo como lesões vesiculares agrupadas que podem ulcerar rapidamente. Estas lesões são observadas frequentemente no pálato e, muitas vezes, são unilaterais, podendo haver apenas eritema. Adequada higiene oral e profilaxia antimicrobiana, local ou sistêmica, podem ajudar a prevenir as infecções orais e reduzir a gravidade da mucosite.

Sangramentos, às vezes difíceis de controlar, ocorrem frequentemente, tanto nas margens gengivais, como nas lesões da mucosa. Além da transfusão de plaquetas, medidas locais incluem a aplicação tópica de gelo, e de pressão local com gaze embebida com trombina. Além da dor produzida pela ulceração da mucosa, que costuma ser muito intensa e degradante para o paciente, o envolvimento dos nervos bucais pela mucosite pode causar dor odontogênica, semelhante à pulpite, de início agudo, unilateral e também muito incômoda para o paciente.

\subsubsection{Cuidados de enfermagem para a mucosite}

Um dos principais objetivos do tratamento de pacientes submetidos à terapia oncológica, incluindo os submetidos ao TMO, deve ser a prevenção de complicações da quimio e radioterapia. Em relação às condições da cavidade oral, os pacientes devem ser avaliados préviamente ao transplante para se identificar os fatores de risco para mucosite grave, principalmente a presença de lesões estabelecidas e o conhecimento e adesão do paciente à prática da higiene oral. Idealmente, esta avaliação deve ser feita pelo dentista e complementada pelo enfermeiro e pelo médico.

Ao se iniciar o condicionamento, a avaliação diária da cavidade oral, pelo médico e pelo enfermeiro, bucará identificar alterações objetivas e subjetivas da mucosa, sugestivas de mucosite ou infecção e monitorizar a eficiência das medidas de higiene empregadas pelo paciente. Vários sistemas, descritivos ou quantitativos, têm sido sugeridos para medir a gravidade da mucosite ${ }^{(17,18)}$.

Em nossa Unidade Charão, et al. em 1999(18a) avaliaram a integridade das cavidades intra e extrabucais e através de suas caracteristicas (coloração, vascularização, lubrificação, integridade, lesões, edemas, sangramento e dor), além das alteraçoes da voz, presença de náuseas e vômitos, analgesia e aceitação alimentar, encontraram alto percentual de acometimento das diferentes estruturas orais durante o período de mucosite após o transplante de medula ossea.

Estabelecida a mucosite, a higiene oral deverá se ajustar à natureza das lesões, buscando-se remover os tecidos necróticos sem agravar o dano tecidual. Para isto, são utilizadas escovas dentais macias, esponjas e compressas, ao lado de tratamento tópico com soluções salinas, anestésicos e lubrificantes. Em nossa Unidade, empregamos uma solução. ("Fórmula para Mucosite"), contendo um anti-inflamatório (benzidamida), um antifúngico (nistatina) e um anestésico (neututocaína).

Em consequência da dor e da inflamação oral, a mucosite contribui significativamente para reduzir a ingestão alimentar no período pós-transplante imediato. Neste período, devem ser evitados alimentos irritantes, condimentados, picantes ou cítricos, de consistência espessa ou áspera, que podem causar abrasão na mucosa oral. Alimentos frios e líquidos são melhor tolerados. Quando o paciente não consegue ingerir as calorias necessárias ao seu metabolismo, usa-se a alimentação parenteral total (vide Secção 3).

Em relação aos sintomas da mucosite, a atenção à dor é prioritária, através de medicações tópicas, orais ou parenterais, dependendendo da gravidade do processo e da capacidade de deglutição do paciente. Mucosite severa, acompanhada de extensas ulcerações, geralmente produz dor intensa que exige o uso de narcóticos por via endovenosa (geralmente meperidina 10-20 mg ou morfina 1-2 mg, inicialmente em bolo a cada 2 a 4 horas ou por infusão contínua controlada por bomba de infusão). Podem ser usados também fentanil, cujos efeitos são similares aos da morfina, e o tramadol. Apesar de prescrita pelo médico, o ajuste da dose dos narcóticos é feito em conjunto pelo enfermeiro e o próprio paciente, levando-se em conta a intensidade dos sintomas e dos efeitos colaterais, principalmente sobre o estado de consciência e sobre a função respiratória.

Assim, a presença constante do enfermeiro, nesta fase, é indispensável para avaliação das condições clínicas do paciente, sua resposta terapêutica e, não menos importante, para proporcionar-lhe suporte emocional, através da empatia, toque e confortamento. De fato, a mucosite representa, em geral, o 
primeiro grande impacto sintomático do período póstransplante e o paciente experimenta, neste período, sentimentos intensos de medo, tristeza, irritação e insegurança, necessitando de assistência de enfermagem individual e constante. Mesmo após a superação desta fase, o desconforto da mucosite permanece, para o paciente, como uma das experiências mais marcantes do TMO.

Outro aspecto fundamental do manejo terapêutico do paciente com mucosite, no qual a equipe de enfermagem desempenha um papel relevante, é a educação do paciente e seus familiares para conhecerem os sintomas a que estarão sujeitos, os fatores de riscos e, principalmente, participarem dos cuidados dispensados. Em decorrência do estreito convívio mantido com o paciente e seus familiares, o enfermeiro tem a oportunidade e a responsabilidade de instruí-los sobre o que esperar do procedimento e como colaborar para seu sucesso, após avaliar o contexto intelectual e social em que estão inseridos.

Apesar de todo o tempo e atenção dispensados à educação do paciente no seguimento ambulatorial prévio ao transplante, nas reuniões pré e pós-internação, observa-se comumente a atitude de negação e regressão do paciente diante das complicações do TMO, a primeira das quais costuma ser a mucosite. A fim de entender melhor este processo, desenvolvese atualmente na Unidade de TMO do HCFMRPUSP um projeto de investigação sobre o significado da mucosite para o paciente, à luz da teoria comunicacional de Morris (1976) ${ }^{(18 b)}$ e a identificação deste processo e suas conseqüências pela enfermagem ao interagir com o paciente. Uma vez completado, este projeto poderá estabelecer estratégias que visam a ajudar o paciente a conceituar adequadamente seus problemas e a enfrentá-los, participando no desenvolvimento de auto-cuidados.

\section{ASPECTOS NUTRICIONAIS DO TRANS- PLANTE DE MEDULA ÓSSEA}

\subsection{Introdução}

A terapia nutricional enteral e parenteral é amplamente utilizada, por várias razões, sendo uma das mais importante, o fato de que má-nutrição é comum em paciente hospitalizado e submetido ao transplante de medula óssea (TMO) ${ }^{(19,20)}$. Durante o curso do TMO ocorrem, rotineiramente, dois fatos distintos e simultâneos que irão interferir no estado nutricional dos pacientes, a diminuição da ingestão de alimentos e o o aumento das necessidades metabólicas. Os pacientes submetidos a transplante de medula óssea, particularmente com doença do enxerto-contra-hospedeiro, podem apresentar anorexia, náuseas e vômitos persistentes, hipogeusia, disgeusia, mucosite, diarréia e conseqüiente ingestão oral insuficiente de nutrientes, com piora do estado geral e nutricional ${ }^{(21-23)}$. A diminuição da ingestão de alimentos decorre principalmente da terapia de citorredução, onde altas doses de drogas quimioterápicas, analgésicos e antibióticos são administrados, causando náuseas, vômitos repetitivos, de difícil controle e alteração da salivação. Ocorre hipogeusia e disgeusia ${ }^{(22)}$; além do aparecimento da mucosite dolorosa na região de orofaringe e esôfago em decorrência também da citorredução. A função intestinal é alterada, resultando em má absorção e, como resultado, ocorre diarréia aquosa na primeira semana pós-quimioterapia ${ }^{(21)}$. Essa terapia de citorredução causa uma neutropenia profunda por 12 a 21 dias e, neste período, há maior susceptibilidade a infecções por bactérias e fungos ${ }^{(24)}$. Devido à neutropenia, os pacientes ficam internados em sistema de isolamento protetor com o máximo de cuidados nas técnicas de assepsia e, com relação à alimentação, esta também deve conter o mínimo de bactérias para evitar infecção que pode ser veiculada através dos alimentos.

De maneira específica, a manutenção de um bom estado nutricional é especialmente importante em todo processo do TMO, sendo a oferta adequada de nutrientes objeto freqüente de estudos e aparentemente fundamental para o sucesso do procedimento ${ }^{(25)}$. Entende-se como oferta adequada a ingestão/infusão de nutrientes necessários para manutenção do metabolismo protéico e energético, em situação de trauma, sem no entanto, ser necessário suplementos extras. Em especial, há boa correlação entre a ingestão correta de alimentos e melhor tolerância a quimioterapia, radioterapia, manutenção da massa corpórea magra, recuperação dos tecidos lesados e diminuição do risco infeccioso ${ }^{(25)}$. Por outro lado, a suplementação nutricional, além das necessidades, parece não alterar a sobrevida, durantes os primeiros 150 dias pós-transplante, de portadores de leucemia mieloide aguda, submetidos a transplante de medula óssea ${ }^{(26)}$.

Em todas as fases do TMO (pré-transplante, citorredução, pós-transplante e pós-alta), são necessárias a identificação e prevenção da desnutrição e a conseqüente oferta de nutrientes de acordo com esta- 
do nutricional do paciente, com um controle rigoroso da ingestão de alimentos. Na Unidade de Transplante de Medula Óssea (UTMO) do Hospital das Clínicas da Faculdade de Medicina de Ribeirão Preto-Universidade de São Paulo, o acompanhamento nutricional dos pacientes internados é feito por nutricionista, em conjunto com a equipe multiprofissional responsável pelo atendimento global do paciente. O nutricionista, ao lado da equipe médica, faz a avaliação e a adequação da ingestão alimentar, sugere o início da terapia nutricional quando a alimentação por via oral não satisfaz as necessidades e participa da reunião diária junto com a equipe multi-profissional para discussão das condutas adotadas. O principal objetivo do atendimento nutricional é manutenção e/ou recuperação do estado nutricional, minimizando ou evitando a perda de peso e as deficiências nutricionais decorrentes da terapia de citorredução. Vista também a implementar um plano dietoterapêutico que atenda às exigências individuais do paciente, evitando a desnutrição e suas complicações.

\subsection{Identificação da desnutrição}

A terapia nutricional agressiva é geralmente oferecida ao paciente identificado como portador de má-nutrição, naqueles em que se prevêem períodos de oferta insuficiente de nutrientes, ou ainda, naqueles que serão submetido a trauma orgânico intenso, resultando em perda de massa corporal. A identificação do paciente desnutrido é feita com base de critérios objetivos, obtidos por meio da história clínica alimentar, exame físico, antropometria e exames bioquímicos, destacando-se as medidas antropométricas, como peso e pregas cutâneas, e a albuminemia. Não existe um simples medida, altamente específica e sensível, para desnutrição. A história clinica de perda ponderal progressiva, sem causa aparente, é, muitas vezes, um dos fortes indicadores de risco de má-nutrição. A magnitude do trauma a que será submetido o paciente também é indicador importante de risco. Quanto mais grave o estado nutricional pregresso, maior o benefício demonstrado da terapia nutricional. Paralelamente, o aumento das necessidades metabólicas ocorre em presença de febre, infecções e, principalmente, na presença da doença do enxerto contra o hospedeiro (GVHD). Nestes casos, há envolvimento do trato gastrintestinal, que resulta em náuseas, vômitos, diarréia, anorexia, perda de peso e má absorção, comprometendo o estado nutricional ${ }^{(27)}$. A tabela II apresenta indicadores importantes do comprometi- mento do estado nutricional, os quais, quando presentes, estão relacionados com maior fator de risco global para o paciente.

\subsection{Terapia Nutricional no TMO}

Em todas as fases de tratamento, a dieta deve ser balanceada, isto é, a oferta energética deve ser adequada para o peso e altura do paciente, a oferta protéica deve conter proteínas digeríveis com todos os aminoácidos essenciais, além de incluir minerais e vitaminas. Sempre que possível, os hábitos do paciente devem ser respeitados.

Durante a internação, a dieta oferecida terá condições de preparo, limites e composição especiais, muitas vezes ela é conhecida como dieta de "citorredução". Esta dieta é oferecida quando o número de glóbulos brancos é inferior a $500 / \mathrm{mm}^{3}$. Nela, são excluídas preparações com ovos e carnes em geral, cruas ou cozidas de maneira inadequada. O leite não pasteurizado, bem como frutas naturais e queijos preparados com leite não pasteurizado, também são excluídos. Alimentos trazidos pelos familiares também não são recomendados. Em todas estas situações de exclusão, os alimentos podem conter agentes patogênicos infecciosos indesejáveis.

Nos pacientes que apresentam doença do enxerto-contra-hospedeiro, com maior envolvimento do trato gastrintestinal, Gavreau-Stern et al. ${ }^{(28)}$ recomendam que a terapia nutricional seja feita em cinco está-

\section{Tabela II - Identificação do paciente desnutrido*}

1. Perda progressiva de peso sem razão aparente.

2. Perda de mais de $10 \%$ do peso usual.

3. Previsão de período de hipermetabolismo duradouro.

4. Índice de massa corporal menor que $18 \mathrm{~kg} / \mathrm{m}^{2}$.

5. Albuminemia menor que $2,8 \mathrm{~g} / \mathrm{dL}$

6. Náuseas e vômitos mantidos que impossibilitem ingestão oral de alimentos.

7. Diarréia / disenteria mantida.

8. Previsão de período de ingestão de nutrientes menor que $1000 \mathrm{kcal} / \mathrm{dia}$ maior que 7 dias em pacientes com índice de massa corporal prévio maior que 18 $\mathrm{kg} / \mathrm{m}^{2}$. Quando este índice for inferior a 18, não esperar por mais de 5 dias. Naqueles pacientes que tiverem valores menores que $15 \mathrm{~kg} / \mathrm{m}^{2}$, iniciar a terapia nutricional imediatamente.

Considerar como de alto risco para desnutrição todo paciente que apresentar pelo menos um dos itens listados 
gios progressivos: 1) Nutrição parenteral total; 2) Introdução de líquidos isotônicos livres de lactose e resíduos; 3) Introdução de alimentos sólidos sem lactose, fibra, gordura e irritantes gástricos; 4) Introdução de alimentos sólidos com aumento de gorduras e 5) Introdução dos alimentos restritos, um por dia, até alcançar a dieta habitual. Interrompe-se a nutrição parenteral quando a oferta via oral for no mínimo metade do planejado. A progressão de um estágio para o outro é avaliada clinicamente pela melhora da sintomatologia e dos sinais clínicos apresentados pelos pacientes.

A utilização de nutrientes específicos com efeitos imunofarmacológicos é um dado promissor para o futuro. Entre estes fatores, destaca-se o uso da glutamina. Assim, a oferta de glutamina em um estudo resultou em menor nível de infecção e menor tempo de hospitalização ${ }^{(29)}$. Por outro lado, em outra investigação ${ }^{(30)}$, o uso de $10 \mathrm{~g}$ de glutamina, 3 vezes por dia, por via oral, ou $0,57 \mathrm{~g} / \mathrm{kg}$ por via parenteral, não resultou em diferenças, quando comparado com placebo, nos seguintes índices: dias totais de hospitalização, permanência hospitalar após o transplante, dias totais de nutrição parenteral, tempo para recuperação do número de neutrófilos $\left(>500 / \mathrm{mm}^{3}\right)$, incidência de hemoculturas positivas, sepse, mucosite e diarréia. Porém, somente 1 em 10 pacientes que receberam glutamina apresentaram GVHD, e no grupo controle, 3 em 10.

Considerando que a terapia nutricional parenteral é freqüentemente utilizada como via de terapêutica nutricional nestes pacientes, é sempre importante considerar os fatores mais associados a maior risco de contaminação do catéter venoso central, ou seja, pela ordem: pacientes submetidos a transplante de medula óssea, a própria nutrição parenteral, o uso do catéter para outras terapias e utilização de cateteres multi-lúmen $^{(31)}$ (veja secção 2.1.).

\subsection{Terapia Nutricional na Unidade de Trans- plante de Medula Óssea da Faculdade de Medicina de Ribeirão Preto (UTMO-RP)}

O nutricionista, sob supervisão e responsabilidade médica, é responsável pela avaliação e evolução nutricional do paciente, bem como pela alimentação oferecida durante a internação na UTMO-RP, tanto no que se refere à supervisão das técnicas de preparo e da qualidade final, quanto da satisfação do paciente e adequação para manutenção do estado nutricional durante o período de internação.
Na UTMO-RP, o plano alimentar é personalizado, de acordo com a história alimentar prévia e o estado nutricional atual. A alimentação oferecida aos pacientes atende às necessidades calóricas e protéicas e é ajustada de acordo com a aceitação e tolerância. A atuação do nutricionista se inicia na reunião de internação, seguida da avaliação nutricional, composta da história e anamnese alimentar, antropometria e estabelecimento das necessidades nutricionais, do planejamento alimentar e do plano dietético durante a internação e após alta, incluindo aí a presença ou não de GVHD.

\subsubsection{Reunião de internação}

Primeiramente, o nutricionista participa da reunião de internação junto com a equipe multiprofissional. Nesta reunião, o paciente conhece toda a equipe e recebe orientações sobre as rotinas e condutas adotadas. As informações com relação à alimentação que se destacam nesta reunião são:

- Função do nutricionista junto à equipe multiprofissional

- Horário das refeições servidas ao paciente e acompanhante.

- Importância do bom estado nutricional durante o período de internação.

- Alimentação com o mínimo de bactérias (sem alimentos crus, ou de procedência duvidosa), consequientemente, é explicado porque são proibidos alimentos que não foram preparados pelo Serviço de Nutrição e Dietética da UTMO.

- Controle da ingestão calórico-protéica.

- Indicação da terapia nutricional adequada.

\subsubsection{Avaliação nutricional}

A avaliação nutricional é realizada, rotineiramente, no ato da internação, porém se, nas consultas de preparação para o TMO, for detectada alteração do estado nutricional, seja por deficiência ou excesso de peso corporal, o paciente é encaminhado ao nutricionista. Este realiza, então, avaliação completa do paciente, indicando a terapia nutricional mais adequada para ajuste do peso corporal, oferecendo uma alimentação balanceada. Os principais itens do protocolo de avaliação nutricional são discutidos a seguir.

\subsubsection{História clínica}

Na história clínica do paciente existem dados importantes para se conhecer seu estilo de vida e seus hábitos pessoais que serão necessários para o plane- 
jamento alimentar e para sua orientação no período da alta hospitalar. Estes dados são: diagnóstico, tipo de transplante (autólogo ou alogênico), procedência, grau de instrução, profissão, condição sócio-econômica, atividade física habitual, aspecto da dentição ou uso de prótese dentária e hábito intestinal. Também são considerados os fatores de risco de desnutrição apresentados na Tabela II, em especial, a história de perda ou ganho recente do peso corporal.

\subsubsection{Anamnese alimentar}

A anamnese alimentar consiste de um interrogatório sobre o dia alimentar habitual do paciente, com o intuito de obter informações que irão auxiliar no planejamento e adequação alimentar durante o período de internação e para orientação da alta hospitalar. Destaca-se, nesta anamnese, a freqüência da ingestão dos alimentos, o fracionamento da alimentação, a quantidade e qualidade dos alimentos ingeridos em cada refeição, crenças e tabus e/ou preferências e intolerâncias alimentares.

\subsubsection{Dados antropométricos}

São necessários para a classificação do estado nutricional $^{(32-33)}$. Estes dados são: sexo, idade, estatura, peso corporal atual, índice de massa corporal e pregas cutâneas (tríceps, circunferência do ponto médio do braço e da musculatura do braço). Em crianças faz-se a relação do peso corporal com a estatura e estatura com a idade.

\subsubsection{Necessidades nutricionais}

Para estimativa da necessidade calórica em adultos, usa-se a equação de Harris \& Benedict ${ }^{(34)}$, que vai calcular o gasto energético basal (GEB) e o gasto energético total (GET), multiplicando-se o GEB pelo fator atividade 1,2 ou pelo fator injúria 1,2 a 1,7, dependendo da intensidade do trauma ${ }^{(35)}$. Em crianças e adolescentes, o gasto energético total (GET) é estimado por meio de tabelas apropriadas ${ }^{(36)}$. As recomendações sobre oferta de proteínas vão depender da idade do paciente e do peso corporal ideal esperado para estatura (Tabela III).

\subsubsection{Plano alimentar}

O plano alimentar é elaborado individualmente por meio de dados colhidos na anamnese alimentar. A alimentação oferecida aos pacientes deve atender às necessidades calóricas e protéicas e ser ajustada de acordo com a aceitação e tolerância do paciente, mas dentro do padrão e disponibilidade hospitalar. A alimentação é preparada com alimentos cozidos adequadamente, líquidos fervidos, alimentos industrializados (pasteurizados ou esterilizados), visando oferecer ao paciente alimentos com o mínimo de agentes patogênicos indesejáveis. São proibidos alimentos in natura ou crus ou ainda de procedência duvidosa. Estes cuidados se devem ao fato da terapia de citorredução deixar o paciente imunodeprimido, isto é, mais susceptível a infecções que podem ser veiculadas pelos agentes patogênicos contidos nos alimentos.

\subsubsection{Alimentação com o mínimo de agentes patogênicos infecciosos}

$\mathrm{Na}$ UTMO, os pacientes internados recebem cinco refeições ao dia (desjejum, almoço, lanche, jantar e complemento da noite). Todos os alimentos oferecidos passam pelo processo de cocção (cozidos, fritos, grelhados ou assados) e os líquidos são fervidos ou autoclavados.

Para o desjejum, lanche e complemento da noite foram elaborados jogos de cardápios com opções que atendem às diferentes dietas prescritas ou que atendem as preferências individuais. Os alimentos são preparados por funcionário devidamente paramentado com avental, luvas e máscara. Após o preparo, são fracionados em embalagens descartáveis identificadas com etiquetas contendo data e nome do paciente e envoltas em sacos plásticos para proteção. Essa proteção é retirada na ante-sala. Os líquidos quentes como, por exemplo, leite, chá e café são dispensados em garrafas térmicas para a manutenção da temperatura e também envoltas em sacos plásticos. As refeições do almoço e jantar são preparadas no Serviço de Nutrição e Dietética do hospital e, tão logo estejam

\begin{tabular}{|lc|}
\hline $\begin{array}{l}\text { Tabela III - Recomendações de oferta protéica em } \\
\text { pacientes submetidos ao transplante de medula } \\
\text { óssea }\end{array}$ \\
\hline Idade (anos) & $\begin{array}{c}\text { Proteína oferecida } \\
\text { (g/Kg de peso corpóreo ideal) }\end{array}$ \\
\hline adultos > 19 anos & 1,5 \\
$15-18$ & 1,8 \\
$11-14$ & 2,0 \\
$7-10$ & 2,4 \\
$4-6$ & $2,5-3,0$ \\
$1-3$ & $2,5-3,0$ \\
\hline
\end{tabular}


prontas, são colocadas em recipientes de alumínio (marmitex), fechados com tampa própria, identificados e levados ao forno elétrico pré-aquecido por 10 minutos para que mantenha a temperatura sem facilitar o crescimento bacteriano. Ao sair do forno, o marmitex é colocado em uma bandeja, também envolta em saco plástico, que é também usado para os talheres descartáveis.

A água para beber passa pelo processo de autoclavagem em frascos de vidro com capacidade de 2 litros. Após resfriamento, são também envoltos em sacos plásticos e guardadas no refrigerador. Para ingestão de líquidos, são fornecidos copos descartáveis.

\subsubsection{Alimentos Proibidos}

Além dos cuidados de higiene pessoal do manipulador de alimentos, do ambiente e dos utensílios, alguns alimentos são proibidos, tais como: leite e derivados in natura e não pasteurizados; carnes de boi, porco, peixe e aves cruas ou mal passadas; ovos quentes (clara e gema mal cozidas) ou ovos fritos de consistência mole; salsicha, bacon, lingüiça, presunto, mortadela, defumados crus ou mal cozidos; ervas aromáticas, por exemplo, orégano, pimenta, manjericão, cominho e chás; frutas frescas cruas; verduras e hortaliças cruas; bolos e doces recheados com cremes, compotas, nozes, amendoim; produtos de panificação, como: pães recheados, pizzas, salgados em geral, tortas, doces e biscoitos recheados; sucos de frutas e vegetais crus; mel não pasteurizado e cru; alimentos de fabricação caseira (sem certificado de qualidade).

\subsubsection{Registro alimentar}

A ingestão alimentar dos pacientes é avaliada diariamente através de um impresso próprio de registro alimentar, onde os pacientes ou seus acompanhantes descrevem o horário e a quantidade de cada alimento que foi ingerido durante o dia. Com este registro, faz-se o cálculo de calorias e proteínas por meio de tabela de composição de alimentos. Quando o cálculo da ingestão for menor que a necessidade do paciente, tenta-se incrementar com complementos ou suplementos nutricionais, tais como Sustagen, mingau enriquecido com gema de ovo, Mucilon, aveia, farinha láctea, fubá, maisena ou outras farinhas, sopas enriquecidas com módulos de proteínas ou de hidratos de carbono, uso de dieta enteral com sabor por via oral, etc. Naqueles pacientes que é detectada ingestão de nutrientes aquém as suas necessidades, iniciase a terapia nutricional precocemente, isto é, antes do dia do TMO.

\subsection{Terapia nutricional parenteral}

A terapia nutricional enteral não é utilizada no período pós-citorredução imediato, devido às complicações, como náuseas, vômitos, diarréia, mucosite e esofagite. Preferencialmente, a terapia nutricional é feita pela nutrição parenteral total (NPT) e é iniciada quando a ingestão alimentar, por via oral, for inferior a $60 \%$ do GET por 3 a 5 dias, acompanhada de perda de peso corporal ou de GVHD intestinal confirmado por exame endoscópico e biopsia ${ }^{(25)}$.

A terapia nutricional via parenteral ${ }^{(35)}$ é indicada para todo paciente submetido a transplante de medula óssea com grave comprometimento do tubo digestivo, incluindo a mucosite que impeça ingestão oral ou permanência de sonda enteral. De uma maneira resumida, o cálculo dos nutrientes ${ }^{(36)}$ necessários é feito a partir do peso atual do paciente, como apresentado na Tabela IV. As Tabelas V e VI apresentam recomendações de minerais e vitaminas. A principais complicações da terapêutica estão apresentadas na Tabela VII e a Tabela VIII mostra os indicadores mínimos a serem utilizados na monitorização e evolução da terapia nutricional parenteral. Sempre que for necessária a utilização de soluções contendo hidratos de carbono, lípides, fósforo e cálcio, em um mesmo frasco, recomenda-se a utilização de filtros para se evitar que partículas com diâmetro superiores ao da hemácea entrem em circulação ${ }^{(36 a)}$. Estas partículas, em geral, são compostas de aglomerados de lipídios ou cristais de fosfato de cálcio amorfo.

A transição da NPT para alimentação via oral se dá quando houver melhora da mucosite e da neutropenia. Os alimentos são introduzidos conforme a tolerância do paciente, iniciando com líquidos e alimentos pastosos, evoluindo até a alimentação habitual. A suspensão da NPT deve ocorrer gradativamente diminuindo-se a $1 / 3$ ou 1/2 conforme a aceitação alimentar. A NPT é suspensa quando a ingestão por via oral ultrapassar $1000 \mathrm{Kcal} / \mathrm{dia}$ ou for maior que $60 \%$ do $\operatorname{GET}^{(37-40)}$.

\subsection{Alta hospitalar}

Um dos critérios para a alta hospitalar é que a aceitação alimentar por via oral esteja adequada. Os pacientes então recebem orientação dietética por escrito, que visa a uma alimentação fracionada, contendo todos os grupos de alimentos, sendo reforçada a importância da ingestão de líquidos, e o preparo de alimentos com o mínimo de bactérias por até 100 dias após o transplante alogênico ou até 60 dias no autológo, 


\section{Tabela IV - Seqüência de passos para o cálculo da terapia nutricional parenteral}

\begin{tabular}{|c|c|c|}
\hline & & Exemplo: paciente de $60 \mathrm{~kg}$ \\
\hline \multirow[t]{2}{*}{1.} & 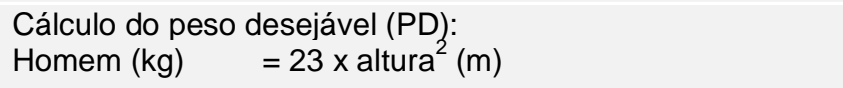 & \\
\hline & Mulher $(\mathrm{kg}) \quad=22 \times$ altura $^{2}(\mathrm{~m})$ & \\
\hline 2. & Oferta protéica inicial $=\mathrm{PD} \times(0,8$ a 1,5$) \mathrm{g} / \mathrm{dia}$ & 48 a $90 \mathrm{~g} / \mathrm{dia}$ \\
\hline \multirow[t]{3}{*}{3.} & $\begin{array}{l}\text { Oferta energética, independente da proteína } \\
\text { Gasto basal= PD x } 30 \mathrm{kcal} / \mathrm{dia}\end{array}$ & \\
\hline & Pacientes c/ trauma leve, aumentar $20-40 \%$ além do basal & \\
\hline & Pacientes grande trauma, aumentar $60-80 \%$ além do basal & \\
\hline 4. & Oferta de lipídios = PD $\times(1,0$ a 1,5$) \mathrm{g} / \mathrm{dia}$ & 60 a $90 \mathrm{~g} / \mathrm{dia}$ \\
\hline 5. & Oferta de hidratos de carbono = PD x (4 a 5) g/dia & 240 a $300 \mathrm{~g} / \mathrm{dia}$ \\
\hline 6. & Minerais e vitaminas (vide tabelas $\mathrm{V}$ e $\mathrm{VI}$ ). & \\
\hline
\end{tabular}

\begin{tabular}{|c|c|c|c|c|}
\hline & Neonatos & Lactentes/Crianças & Adolescentes & Adultos \\
\hline Sódio & $2-5 \mathrm{mEq} / \mathrm{kg}$ & $2-6 \mathrm{mEq} / \mathrm{kg}$ & $50-80 \mathrm{mEq}$ & $50-200 \mathrm{mEq}$ \\
\hline Potássio & $1-4 \mathrm{mEq} / \mathrm{kg}$ & $2-3 \mathrm{mEq} / \mathrm{kg}$ & $40-60 \mathrm{mEq}$ & $30-100 \mathrm{mEq}$ \\
\hline Cloreto & $1-5 \mathrm{mEq} / \mathrm{kg}$ & $2-5 \mathrm{mEq} / \mathrm{kg}$ & $50-220 \mathrm{mEq}$ & $50-220 \mathrm{mEq}$ \\
\hline Cálcio & 3-4 mEq/kg & $1-2,5 \mathrm{mEq} / \mathrm{kg}$ & $10-20 \mathrm{mEq}$ & 3-30 mEq \\
\hline Fósforo & $1-2 \mathrm{mmol} / \mathrm{kg}$ & $0,5-1 \mathrm{mmol} / \mathrm{kg}$ & $10-40 \mathrm{mmol}$ & $10-40 \mathrm{mmol}$ \\
\hline Magnésio & $0,3-0,5 \mathrm{mEq} / \mathrm{kg}$ & $0,3-0,5 \mathrm{mEq} / \mathrm{kg}$ & $10-30 \mathrm{mEq}$ & $10-30 \mathrm{mEq}$ \\
\hline Zinco & $300 \mu \mathrm{g} / \mathrm{kg}$ & $100 \mu \mathrm{g} / \mathrm{kg}$ & $2-5 \mathrm{mg}$ & $2-5 \mathrm{mg}$ \\
\hline Cobre & $20 \mu \mathrm{g} / \mathrm{kg}$ & $20 \mu \mathrm{g} / \mathrm{kg}$ & $0,2-0,5 \mathrm{mg}$ & $0,5-1,5 \mathrm{mg}$ \\
\hline Cromo & $0,2 \mu \mathrm{g} / \mathrm{kg}$ & $0,2 \mu \mathrm{g} / \mathrm{kg}$ & $5-15 \mu \mathrm{g}$ & $10-15 \mu \mathrm{g}$ \\
\hline Manganês & $1 \mu \mathrm{g} / \mathrm{kg}$ & $1 \mu \mathrm{g} / \mathrm{kg}$ & $50-150 \mu \mathrm{g}$ & $150-800 \mu \mathrm{g}$ \\
\hline
\end{tabular}

podendo esse tempo ser prolongado caso paciente permaneça neutropênico ou em tratamento para GVHD. É comum o paciente continuar com disgeusia ou hipogeusia por mais algum tempo, apresentar dificuldade para se alimentar devido náuseas e/ou vômitos, diarréia, intolerância à lactose e ao glúten; nestes casos, o paciente recebe um guia contendo sugestões para melhorar a aceitação alimentar. Por este motivo, o acompanhamento no ambulatório continua com a avaliação da ingestão através dos registros alimentares e o controle do peso corporal.

\subsection{Doença do Enxerto-versus-Hospedeiro Aguda Intestinal}

A GVHD grave (de graus II a IV), em $50 \%$ dos casos, cursa com envolvimento do trato gastrintestinal e apresenta como característica náuseas, vômitos, anorexia, perda de peso, diarréia secretória, alteração da motilidade intestinal, dor e má absorção ${ }^{(27)}$. Neste caso, a terpêutica nutricional é um complemento importante da terapia, a qual deve ser planejada e caracterizada conforme os sintomas clínicos e a tole- 


\begin{tabular}{|c|c|c|c|}
\hline Vitaminas & Neonatos $<1,5 \mathrm{~kg}$ & Lactentes/crianças & Adultos \\
\hline$A-U I$ & 1400 & 2300 & 3300 \\
\hline D - UI & 240 & 400 & 200 \\
\hline E - UI & 4,2 & 7 & 10 \\
\hline Tiamina - $\mathrm{B}_{1}-\mathrm{mg}$ & 0,72 & 1,2 & 3 \\
\hline Riboflavina - $\mathrm{B}_{2}-\mathrm{mg}$ & 0,84 & 1,4 & 3,6 \\
\hline Niacina $-B_{3}-m g$ & 10,2 & 17 & $10-150$ \\
\hline Ác. pantotênico - $\mathrm{B}_{5}-\mathrm{mg}$ & 3 & 5 & 15 \\
\hline Piridoxina - $\mathrm{B}_{6}-\mathrm{mg}$ & 0,6 & 1 & 4 \\
\hline Biotina $-\mathrm{B}_{7}-\mu \mathrm{g}$ & 12 & 20 & 60 \\
\hline Ác. fólico - Bg - $\mu \mathrm{g}$ & 84 & 140 & 400 \\
\hline Cianocobalamina - $\mathrm{B}_{12}-\mu \mathrm{g}$ & 0,6 & 1 & 5 \\
\hline Ác. ascórbico - C - mg & 48 & 80 & 100 \\
\hline
\end{tabular}

Tabela VII - Complicações da terapia nutricional via parenteral.

\begin{tabular}{|c|c|c|c|}
\hline & Primeiras 48 horas & Primeiras 2 semanas & Tardias \\
\hline Mecânicas & $\begin{array}{l}\text { Devidas à inserção do } \\
\text { catéter (Sec. 1.2): } \\
\text { pneumotórax, trauma local, } \\
\text { embolia, perda de sangue, } \\
\text { enfisema subcutâneo, lesão } \\
\text { pulmonar, etc }\end{array}$ & $\begin{array}{l}\text { Deslocamento, torção e } \\
\text { quebra do catéter }\end{array}$ & Idem \\
\hline Metabólicas & $\begin{array}{l}\text { Sobrecarga hídrica, } \\
\text { hiperglicemia, } \\
\text { hipofosfatemia, hipocalemia, } \\
\text { etc. }\end{array}$ & $\begin{array}{l}\text { Coma hiperosmolar não } \\
\text { cetótico, desequilíbrio } \\
\text { ácido-base, alterações } \\
\text { eletrolíticas ( } \mathrm{P}, \mathrm{Mg}, \mathrm{Na}, \mathrm{K} \text { ) }\end{array}$ & $\begin{array}{l}\text { Deficiências de } \\
\text { micronutrientes (Zn, } \mathrm{Cu} \text {, } \\
\mathrm{Cr}, \mathrm{Se}, \mathrm{Mb}, \mathrm{Fe}) \text {, de } \\
\text { vitaminas e de ácidos } \\
\text { graxos essenciais. Doença } \\
\text { óssea e hepática } \\
\text { associada à nutrição } \\
\text { parenteral prolongada }\end{array}$ \\
\hline Infecciosas & $\begin{array}{l}\text { Infecção local, no orifício de } \\
\text { entrada ou no túnel (tunelite) }\end{array}$ & $\begin{array}{l}\text { Idem mais sépsis induzida } \\
\text { pela má manutenção ou } \\
\text { uso inadequado do catéter }\end{array}$ & Idem \\
\hline
\end{tabular}


Tabela VIII - Monitorização e indicadores mínimos a serem utilizados na evolução da terapia nutricional via parenteral.

1. Aspectos gerais: sintomas que sugerem sobrecarga hídrica ou deficiência de líquidos, de glicose, de eletrólitos, etc. Balanço hídrico.

2. Controle do peso e medidas antropométricas. Peso - $\mathrm{kg}$ e altura $-\mathrm{m}$. Cálculo do índice de massa corporal = $\mathrm{IMC}=$ peso/altura ${ }^{2}=\mathrm{kg} / \mathrm{m}^{2}$.

3. Verificação da oferta de nutrientes

4. Cuidados gerais de controle de infecção

5. Monitorização laboratorial. Controle de glicemia e eletrólitos (corrigir clinicamente sempre que necessário)

rância alimentar do paciente ${ }^{(28)}$, em um plano alimentar com cinco estágios distintos, (vide Secção 3.3):

1) Nutrição parenteral total (NPT)

2) Introdução de líquidos isotônicos livres de lactose

3) Introdução de alimentos sólidos sem lactose, fibra, gordura e irritantes gástricos

4) Introdução de alimentos sólidos com aumento de gorduras

5) Introdução dos alimentos restritos, um por dia, até alcançar a dieta habitual

\subsubsection{Dieta para GVHD intestinal}

O paciente com diagnóstico de GVHD agudo de grau II a IV com volume de diarréia maior do que $500 \mathrm{ml} /$ dia deve permanecer em jejum por um período de 3 a 10 dias, recebendo NPT, de acordo com o exposto no item 3.5. Tão logo apresente melhora da diarréia, deve iniciar a dieta de evolução, conforme esquema exposto abaixo (Tabela IX) ${ }^{(28)}$.

\section{Caso clínico ilustrativo $\mathbf{N}^{0} 1$}

Paciente: L.J.L.V., feminina, branca, 44 anos, portadora de leucemia mielóide crônica em $1^{a}$ fase crônica, diagnosticada em $8 / 98$, realizado TMO alogênico HLA-idêntico em 17/01/2000, enxertia no dia +14 pós-TMO, alta hospitalar no dia +19 .

Avaliação nutricional na internação: Peso corporal: $60,2 \mathrm{Kg}$, Estatura: 1,52 m, Peso habitual: $78,0 \mathrm{Kg}, I M C: 26,0 \mathrm{Kg} / \mathrm{m}^{2}$ - Classificação: sobrepeso

Peso ideal esperado: mínimo $=42,7 \mathrm{Kg}$, máximo $=57,5 \mathrm{Kg}$, médio $=49,5 \mathrm{Kg}$.

Necessidade nutricional: Gasto energético basal: $1250 \mathrm{Kcal}$, Gasto energético total: 1800 Kcal, Proteínas: $72 \mathrm{~g} / \mathrm{dia}$ (1,2 $\mathrm{g} / \mathrm{Kg}$ de peso corporal)
Evolução dietoterápica durante o pós-TMO imediato:Paciente manteve alimentação adequada por via oral até $D-4$, quando iniciou com náuseas e vômitos, diminuindo a ingestão alimentar. Foi iniciada terapia nutricional oral com dieta enteral com sabor, a qual acrescentava $600 \mathrm{Kcal}$ dia. No D+6 iniciou a nutrição parenteral total (NPT), devido ao aparecimento da mucosite com

Tabela IX - Dieta de evolução para GVHD intestinal

\section{Dieta de evolução I:}

Água, à vontade.

Chá com dextrina/maltose, $100 \mathrm{ml}, 3$ vezes ao dia.

Água de coco, $200 \mathrm{ml}, 2$ vezes ao dia.

Obs.: Aumentar a quantidade dos líquidos, quando bem tolerados. Permanecer por 3 ou mais dias se necessário.

\section{Dieta de evolução II:}

Introduzir sopa líquida hipogordurosa sem resíduo.

Sopa de legumes, $150 \mathrm{ml}, 2$ vezes ao dia.

Obs.: Aumentar a quantidade oferecida e acrescentar caldo de carne. Permanecer por 3 ou mais dias.

Dieta de evolução III:

Dieta pastosa hipogordurosa sem resíduos, 2 vezes ao dia.

Gelatina dietética e fruta cozida.

Obs.: Permanecer por 1 ou 2 dias.

\section{Dieta de evolução IV:}

Introduzir alimentos cozidos e glúten.

Dieta branda sem lactose.

Obs.: Permanecer por 1 ou 2 dias.

Dieta de evolução V:

Introduzir a lactose.

Dieta geral sem alimentos crus.

O paciente durante a dieta de evolução poderá retroceder, isto é, da dieta de evolução III, voltar para a I, caso haja piora do quadro clínico ou aumento do volume de diarréia. O término da NPT vai depender da aceitação da dieta de evolução, devendo ser retirada quando a ingestão alcançar $1000 \mathrm{Kcal} /$ dia. Ref. (28). 
dificuldade para deglutir e perda de peso de 1,6 Kg. No D+14 apresentou melhora da mucosite e início da alimentação via oral. Permaneceu com NPT, que fornecia $2300 \mathrm{Kcal}$ (calorias não protéicas e $75 \mathrm{~g}$ de proteína) até $\mathrm{D}+17 \mathrm{com}$ ingestão calórica de $1300 \mathrm{Kcal}$. No D+19 recebeu alta hospitalar com peso corporal de $56,4 \mathrm{Kg}$.

Complicações pós-alta: No dia +130 , desenvolveu GVHD leve de pele, que não necessitou de tratamento. No dia +140 foi detectada recaída molecular e citogenética da LMC e no dia +143 foi internada para quimioterapia de crise blástica do tipo linfóide, com peso de $59 \mathrm{~kg}$. No dia $+158 \mathrm{re}$ cebeu infusão de linfócitos do doador (DLI), tendo alta hospitalar no dia +171 . No dia +177 ( $D$ +23 pós DLI) foi reinternada com anorexia, obstipação intestinal e dor abdominal. No dia seguinte, desenvolveu GVHD de pele de intestinal, com diarréia aquosa esverdadeada de grande volume $(1100 \mathrm{ml})$, perda de peso $(54,200 \mathrm{~kg})$, sendo iniciados jejum, NPT e tratamento com corticóides. No dia +187 o volume da diarréia aumentou para $3200 \mathrm{ml}$, mas uma semana depois (D +194), diminuiu para $600 \mathrm{ml} / \mathrm{d}$, o peso subiu para $57,8 \mathrm{~kg}$ e foi iniciada dieta de evolução I. Houve melhora progressiva, com redução da diarréia e aumento do peso (para $55 \mathrm{~kg}$ ) e no $D+211$ foi introduzida dieta de evolução IV, com boa aceitação. Entretanto, a partir do D +214 , desenvolveuse um quadro neurológico de etiologia indefinida, provavelmente infeccioso, com aumento da diarréia $(1350 \mathrm{ml} / \mathrm{d})$, forçando um retorno para dieta de evolução I, com pequena aceitação e aumento da NPT. No dia +220 , o volume de diarréia diminuiu para $200 \mathrm{ml}$, com a intensificação do tratamento da GVHD, mas no dia +223 , evoluiu para insuficiência respiratória e óbito.

Comentários: A dieta padronizada para GVHD intestinal foi bem sucedida, pois o objetivo de introduzir os alimentos gradativamente, conforme a melhora da diarréia, foi alcançado. Alguns problemas previsiveis ocorreram, como: medo da paciente para se alimentar e apresentar vômitos, intolerância a muitos tipos de alimentos, chegando a não aceitar nenhum tipo de chá, ficando na dieta de evolução I apenas com água e água de coco. O preparo da sopa teve que ser adaptado, pois alguns legumes a paciente também não aceitava. Por fim, conseguiu receber a dieta IV, mas houve recidiva da GVHD, forçando a intensificação da imunossupressão e o retorno para dieta I e a paciente acabou indo a óbito, provavelmente de causa infecciosa.

\section{ASPECTOS FISIOTERAPÊUTICOS DO TRANSPLANTE DE MEDULA ÓSSEA}

\subsection{Introdução}

O fisioterapeuta é parte importante da equipe multidisciplinar necessária para atender as necessidades complexas do paciente submetido ao transplante de medula óssea (TMO) ${ }^{(41)}$.

O longo período de isolamento protetor necessário para o tratamento restringe as atividades físicas do paciente, o que, associado à toxicidade dos agentes quimioterápicos utilizados no regime de condicionamento pré-transplante, pode potencializar os efeitos deletérios para o sistema cardiopulmonar ${ }^{(41,42)}$. Em um estudo realizado por Wingard com pacientes um ano após o TMO, $76 \%$ citavam a fadiga e $41 \%$ a fraqueza como queixas principais ${ }^{(43)}$. Os efeitos adversos provocados pela inatividade ou repouso prolongado no leito podem ser prevenidos ou atenuados através do início precoce da intervenção fisioterápica ${ }^{(44,45)}$. Nas últimas quatro décadas, houve um importante reconhecimento dos efeitos benéficos do exercício físico para pacientes com câncer e há um crescente interesse em que sejam instituídos programas de reabilitação física para estes pacientes ${ }^{(42,46,47)}$.

Devido à fadiga e fraqueza que experimentam durante o procedimento, os pacientes tendem a permanecer em repouso ou diminuir sensivelmente as suas atividades de vida diária (AVD), o que contribui para a manutenção da inatividade e conseqüente descondicionamento (Figura 1) ${ }^{(48)}$. O descondicionamento é definido como uma capacidade funcional reduzida de um ou vários sistemas orgânicos e deve ser considerado como uma condição separada (síndrome do desuso) do processo original que levou à redução da atividade normal $^{(48)}$.

Existem quatro tipos de reabilitação para pacientes com câncer: paliativa, de suporte, restauradora e preventiva ${ }^{(49)}$. Na reabilitação paliativa, os objetivos são diminuir a dependência na execução das atividades da vida diária e proporcionar conforto emocional, aplicando-se prioritariamente a pacientes com doença avançada e curta expectativa de vida. Na etapa de suporte, o objetivo é tratar os déficits que ocorrem a longo prazo para melhorar a função quando há um determinado grau de incapacidade. A reabilitação restauradora visa a restituir a função existente previa- 


\section{O CICLO VICIOSO DA INATIVIDADE}



Figura 1: A inatividade prolongada e o repouso no leito causam uma redução na capacidade funcional de órgãos e sistemas, até que novos sintomas e sinais de descondicionamento apareçam · Modificado de HALAR et al. ${ }^{(48)}$.
A avaliação física visa a identificar limitações na amplitude de movimento, déficits de força muscular e alterações de coordenação e equilíbrio. $\mathrm{Na}$ avaliação respiratória, é fundamental a espirometria forçada para auxiliar no diagnóstico precoce e seguimento evolutivo das disfunções pulmonares ${ }^{(51,52)}$.

Após as avaliações pré-transplante, é iniciada a cinesioterapia motora e respiratória, visto que um fator freqüentemente subestimado que contribui para a diminuição do desempenho físico em pacientes com câncer é a falta da atividade física durante $o$ período de hospitalização ${ }^{(44,45)}$. O uso de corticoes- mente ao tratamento que foi comprometida a curto prazo, por exemplo, uma miopatia causada pelo uso de corticóide. A meta da reabilitação preventiva é introduzir um programa de tratamento que evite prejuízos funcionais já esperados, por exemplo, um programa de condicionamento físico para pacientes submetidos à quimioterapia e/ou radioterapia ${ }^{(49,50)}$.

No programa de transplante de medula óssea do HCFMRP, o trabalho de fisioterapia é realizado em três etapas: 1) atendimento na enfermaria; 2) seguimento ambulatorial; 3) atendimento na reinternação.

\subsection{Atendimento na enfermaria}

Após a admissão do paciente na enfermaria do TMO, é necessário que seja realizada a avaliação física e respiratória antes do início do regime de condicionamento quimioterápico e da ocorrência de seus efeitos colaterais ${ }^{(41)}$. Também é importante que a avaliação possa ser feita préviamente à instalação do catéter no tórax do paciente, o qual poderá limitar a expansão torácica e a mobilidade, pela dor apresentada logo após a cirurgia, principalmente no primeiro e segundo dias após o implante. O fisioterapeuta deve, antes do início do tratamento fisioterápico, estar ciente dos resultados de exames pertinentes, tais como o ecocardiograma, o eletrocardiograma, a radiografia torácica, o hemograma e a espirometria forçada. teróides administrados sistemicamente também contribui para a atrofia e miopatia nos músculos esqueléticos, podendo os músculos respiratórios estar envolvidos neste processo ${ }^{(53) .}$

\subsubsection{Cinesioterapia motora}

A cinesioterapia motora tem o objetivo de reduzir ou prevenir a atrofia muscular de desuso, manter a coordenação, o equilíbrio, a força muscular e a amplitude de movimento. Na posição deitada, a atividade muscular é mínima e a força exercida pela gravidade nos ossos e nos tecidos de apoio é reduzida. Os músculos antigravitacionais do tronco e membros inferiores são, algumas vezes, os primeiros a atrofiar ${ }^{(49)}$. A hipotensão postural grave é um risco comum da prolongada inatividade e repouso no leito.

É importante, portanto, incentivar que o paciente saia frequentemente do leito, procurando realizar a cinesioterapia motora em pé com exercícios de alongamento e fortalecimento muscular, podendo também ser utilizada a bicicleta ergométrica. As orientações posturais devem ser reforçadas com o objetivo de evitar dores musculares decorrentes de uma postura inadequada e o paciente deve ser incentivado a permanecer sentado sempre que for possível. Antes de qualquer tratamento fisioterápico ser iniciado, é importante que sejam considerados os valores de contagem de plaquetas, hemoglobina e hematócrito ${ }^{(53 a)}$. 
- Plaquetas: Se a contagem de plaquetas estiver entre 20.000 a $30.000 / \mathrm{mm}^{3}$, podem ser realizados exercícios ativos leves, sem resistência. Pacientes com contagem de plaquetas acima de $30.000 / \mathrm{mm}^{3}$ podem fazer exercícios ativos moderados, sem resistência. Com plaquetas acima de $50.000 \mathrm{~mm}^{3}$, podem ser realizados exercícios ativos, com resistência. A percussão e as manobra de vibração e compressão torácicas podem ser utilizadas somente com plaquetas acima de $50.000 \mathrm{~mm}^{3}$. A vibração torácica isolada pode ser aplicada com plaquetas acima de $30.000 \mathrm{~mm}^{3}$.

- Hemoglobina $(\mathrm{Hb})$ e hematócrito $(\mathrm{Ht})$ : Se os valores de $\mathrm{Hb}$ estiverem abaixo de $8 \mathrm{~g} / \mathrm{dl}$ e o Ht menor que $25 \%$, podem ser realizados somente exercícios passivos e/ou atividades rotineiras da vida diária. Com $\mathrm{Ht}$ de 25 a $35 \%$ e $\mathrm{Hb}$ entre 8 a $10 \mathrm{~g} / \mathrm{dl}$ podem ser realizadas atividades aeróbias leves. Para valores de $\mathrm{Ht}$ acima de $35 \%$ e $\mathrm{Hb}$ maior que $10 \mathrm{~g} / \mathrm{dl}$, são indicados exercícios aeróbios conforme a capacidade física apresentada pelo paciente.

\subsubsection{Cinesioterapia Respiratória}

A cinesioterapia respiratória tem o objetivo de auxiliar no tratamento e/ou prevenção de infecções respiratórias e microatelectasias ${ }^{(1,49)}$. São empregadas técnicas de expansão pulmonar, as quais utilizam padrões respiratórios com inspiração profunda, visando a atingir a capacidade pulmonar total (CPT). Também é utilizado o incentivador respiratório para terapia com sustentação máxima da inspiração (SMI), o qual é bem aceito pelo paciente pela visualização do exercício.

As complicações pulmonares são responsáveis por 40 a $60 \%$ dos óbitos em pacientes submetidos ao TMO, sendo a intubação oro-traqueal e a ventilação mecânica associadas a um alto índice de mortalidade durante os primeiros 100 dias após o transplante ${ }^{(54,55)}$. Rabitsch et al. (1998) sugerem que a ventilação mecânica não-invasiva (VMNI) pode ser uma alternativa para melhorar o prognóstico dos pacientes do TMO que necessitam de suporte ventilatório ${ }^{(56)}$. Outros autores também têm relatado resultados satisfatórios com outras formas de VMNI, como a pressão positiva contínua nas vias aéreas (CPAP), na qual todo o ciclo ventilatório é realizado com um sistema pressurizado positivo e constante, ou a ventilação com pressão positiva bifásica (BIPAP) ${ }^{(57,58)}$. No modo BIPAP, há uma diferenciação da pressão administrada durante a inspiração (IPAP) e durante a fase expiratória (EPAP), funcionando este último efetivamente como uma pressão positiva ao final da expiração (PEEP) ${ }^{(59)}$.
O caso clínico apresentado abaixo $\left(\mathrm{N}^{\circ} 2\right)$ ilustra o efeito benéfico da instituição precoce de suporte ventilatório, ao lado do tratamento medicamentoso, evitando, provavelmente, a intubação do paciente, a qual apresenta alta mortalidade.

\section{Caso clínico ilustrativo $\mathbf{N}^{0}$ 2:}

JBA, 42 anos, masculino, branco, operário, natural e procedente de Santa Rita do Passa Quatro, São Paulo. Era portador de Mieloma Múltiplo diagnosticado em março de 1997 e foi tratado com protocolo de transplante seriado. Em março de 1998, após quimioterapia mieloablativa com melfalan $200 \mathrm{mg} / \mathrm{m}^{2}$, foi realizado TMO autólogo com infusão de células progenitoras do sangue periférico (CPSP). Foi submetido a um segundo TMO de CPSP em agosto de 1998 dentro do protocolo de transplantes seriados para mieloma. No dia +9 referia dispnéia discreta e a radiografia torácica mostrava velamento bibasal mais importante à direita. Foi realizada broncofibroscopia com lavado broncoalveolar (LBA) e no dia +11 houve piora da dispnéia e do padrão radiológico, apresentando velamento alveolar difuso compatível com processo inflamatório. A frequência respiratória era de $52 \mathrm{ipm}$, a gasometria mostrava $\mathrm{pH}$ 7,51, $\mathrm{PaO}_{2}$ 50, $\mathrm{PaCO}_{2}$ 28, Sat $\mathrm{O}_{2}$ 89. Foi iniciado suporte ventilatório não invasivo com CPAP contínuo através de uma máscara facial com PEEP de $5 \mathrm{cmH}_{2} \mathrm{O}$. O paciente referia conforto com a máscara e foi aumentado o PEEP para $8 \mathrm{cmH}_{2} \mathrm{O}$. No dia +13 permaneceu com CPAP intermitente e havia melhora importante da queixa de dispnéia. Durante esse período, foi feito cinesioterapia respiratória com padrões ventilatórios para expansão pulmonar e cinesioterapia motora ativa-assistida e passiva. $O$ paciente apresentou resposta à terapia antimicrobiana empírica de amplo espectro, evoluindo com resolução do quadro respiratório. Após a alta, continuou com atendimento de fisioterapia ambulatorial.

\subsection{Atendimento Ambulatorial}

O exercício aeróbio vem sendo incentivado para a reabilitação dos pacientes com câncer, com o intuito de melhorar suas condições físicas, além de proporcionar melhora no quadro de depressão freqüentemente apresentado pelos pacientes ${ }^{(60,61)}$. Uma forma de exercício aeróbio que utilizamos em nosso serviço é a orientação de caminhadas para os pacientes, as quais devem, sempre que possível, serem iniciadas assim 
que o paciente possa sair da enfermaria e mantidas após a alta. Devem ser enfatizadas inicialmente as sessões de trabalho aeróbio intervalado com exercícios submáximos (65 a 75\% do máximo), evitando-se o exercício contínuo ${ }^{(42,62)}$. É importante também que sejam realizados outros exercícios capazes de aprimorar a força muscular e a mobilidade global. $\mathrm{O}$ efeito benéfico da atividade física na função imune tem sido descrito, mas o mecanismo exato através do qual ocorre ainda são discutidos. A propósito, Dimeo et al (1997) sugerem em um estudo, no qual foi utilizado o treinamento aeróbio em pacientes submetidos a altas doses de quimioterapia, que o período de internação e da neutropenia foi menor no grupo treinado ${ }^{(42)}$.

\subsection{Reinternação}

A fisioterapia será direcionada para a causa da internação. Por exemplo, complicações respiratórias são uma frequiente causa de reinternação na fase precoce pós-TMO (antes do dia +100 ) e se aplicam as mesmas medidas empregadas no paciente internado (vide Secção 4.2.2).

\subsection{Fisioterapia e complicações do TMO}

Náuseas e vômitos: São decorrentes, inicialmente, das altas doses de rádio/quimioterapia administradas durante o regime de condicionamento prévio ao TMO e, no período de alta, pela reintrodução da dieta e medicamentos por via oral, apresentando intensidade variável para cada indivíduo. A fisioterapia será realizada somente no período no qual o paciente referir melhora dos sintomas ${ }^{(41)}$.

Mucosite: Nesta fase, o paciente apresenta respiração superficializada e maior dificuldade na expectoração devido à dor orofaríngea relacionada ao grau de inflamação e necessidade de analgesia. Devem ser reforçados os exercícios respiratórios com incentivo da inspiração profunda e orientado para que o paciente permaneça sentado pela maior dificuldade na expectoração. Para facilitar a eliminação da sialorréia, o paciente, freqüentemente, assume a posição de flexão de tronco por períodos prolongados, o que leva a dor, principalmente localizada na musculatura cervical. A massagem terapêutica auxilia no relaxamento, aliviando a dor e ansiedade importantes nesta fase.

Doença veno-oclusiva hepática (VOD): A distensão e a dor abdominais tornam desconfortável a permanência em decúbito dorsal. É importante elevar a cabeceira do leito e evitar atividades que forcem a musculatura abdominal. Se a VOD for leve, os exer- cícios ativos com o paciente sentado serão bem tolerados $^{(41)}$.

Febre: No período imediatamente após o TMO, é frequente ocorrer a hipertermia e, sempre que possível, deve ser aguardada a redução da temperatura para que a fisioterapia seja realizada. A febre leva ao aumento da freqüência respiratória (FR), da frequência cardíaca (FC) e do consumo de plaquetas, podendo, assim, interferir com a fisioterapia ${ }^{(41)}$.

Doença do enxerto-contra-hospedeiro (DECH): A DECH aguda ocorre usualmente de 1 a 2 meses após o TMO ${ }^{(63,64)}$. Nesta fase, podem ocorrer cólicas e diarréias causadas pela $\mathrm{DECH}$ intestinal moderada ou leve, que não são agravadas por atividades leves realizadas em pé, sendo, no entanto, contra-indicado o exercício abdominal ${ }^{(41)}$. Nos pacientes que apresentam ardor e prurido nas palmas das mãos e planta dos pés, pode ser mantida a cinesioterapia motora, evitando-se exercícios com permanência prolongada em pé, os quais causam desconforto para o paciente. Quando ocorre DECH de pele mais grave, com eritrodermia e descamação, podem ser utilizados exercícios aeróbios no limite tolerado pelo paciente.

O início da DECH crônica ocorre usualmente, mais de 3 meses após o TMO. No pulmão, a DECH crônica se manifesta como bronquiolite obliterante, devendo ser reforçada a cinesioterapia respiratória $^{(63,64)}$. O sistema músculo-esquelético pode ser afetado e envolver a pele, os músculos esqueléticos e a cápsula articular. Os exames histológicos revelam a presença de um infiltrado inflamatório crônico e fibrose difusa dos tecidos envolvidos, alterações que são responsáveis por contraturas articulares observadas na DECH crônica. A fisioterapia auxilia, prevenindo deformidades que levam à perda funcional, utilizando exercícios com ênfase na manutenção ou melhora da amplitude do movimento articular e uso de splint, se necessário. O sucesso destas intervenções para a melhora da capacidade funcional está ilustrado no caso clínico descrito abaixo.

\section{Caso clínico ilustrativo $N^{o}$ 3:}

VDVJ, 13 anos, masculino, branco, natural e procedente de Pontal- SP, foi submetido a TMO alogênico HLA-idêntico em setembro de 1995 para leucemia aguda bifenotípica. Foi condicionado com bussulfan e ciclofosfamida (BU-CY2), e fez profilaxia de DECH com metotrexate $e$ ciclosporina. Não teve DECH aguda ou crônica pós-transplante. Em março de 1997, no dia +504 pós-TMO, apresentou recaída de doença. Após 
infusões de linfócitos do doador, evoluiu em maio de 1998 com DECH crônica córtico-dependente acometendo pele, fígado, olhos, boca, sistema músculo-esquelético e pulmões, com disfunção ventilatória obstrutiva moderada compatível com quadro de bronquiolite obliterante secundária à DECH pulmonar. Apresentava retrações musculares importantes em membros inferiores e superiores. Passou a fazer acompanhamento de fisioterapia ambulatorial. Na cinesioterapia motora, eram realizados movimentos passivos, ativo-assistidos e ativos com ênfase no alongamento muscular e as mãos foram posicionadas com splints. Para os pulmões, eram aplicadas técnicas desobstrutivas, como drenagem postural associada a exercícios respiratórios, manobra de vibração associada à compressão torácica e aerosol. Apresentou significativa melhora funcional, principalmente na pele e no sistema músculo-esquelético, pela combinação da fisioterapia com o tratamento medicamentoso com ciclosporina, corticoesteróides, talidomida e lidocaína endovenosa. Entretanto, em setembro de 1999 foi a óbito por recaída da doença neoplásica associada a infecção sistêmica.

\subsection{Considerações Finais}

A fisioterapia pode auxiliar no tratamento dos pacientes submetidos ao TMO, melhorando a função global ou auxiliando no tratamento dos sintomas apresentados. Os efeitos benéficos da atividade física para pacientes com câncer são reconhecidos por seu importante impacto na qualidade de vida. O declínio na capacidade física interfere negativamente na realização das atividades de vida diária e no retorno ao trabalho, podendo ser minimizado com a intervenção precoce, evitando assim os períodos prolongados de inatividade.

\section{PAPEL DO SERVIÇO SOCIAL NO TRANS- PLANTE DE MEDULA ÓSSEA}

Dentre as ações desenvolvidas pelo assistente social, destacam-se as de cunho sócio-educativo, cujo objetivo é formar uma rede articulada de apoio ao paciente, dentro e fora da Hospital e extrapolando suas ações para a comunidade local e regional.

No atendimento aos pacientes submetidos ao TMO, as ações do serviço social se iniciam desde o primeiro contato do paciente e familiares com a Unidade de transplante e continua durante todas as fases do procedimento, a níveis ambulatorial e hospitalar, até a reintegração do paciente a sua comunidade, que é o objetivo final do processo.

A Tabela X mostra o espectro de ações do Serviço Social junto ao paciente submetido ao TMO. Para cumprir estas funções, o paciente e seus familiares são submetidos a uma avaliação sócio-econômica logo após ser consubstanciada a indicação médica para o transplante, incluindo a disponibilidade de doador. Após este primeiro contato, é realizada uma reunião com a equipe multiprofissional do TMO com o objetivo de esclarecê-los quanto aos múltiplos aspectos do procedimento, seus riscos e benefícios, possíveis intercorrências e as condições mínimas, sócio-econômicasculturais, para sua realização. Quando necessário, são realizadas visitas domiciliares à residência do paciente para verificar a existência de infra-estrutura adequada para abrigá-lo após a alta. Em algumas situações extremas, o transplante pode ser contra-indicado se o paciente não preencher estas condições, como dispor de um acompanhante confiável e de uma habitação higiênica para prosseguir seu tratamento após o período pós-transplante imediato (100 dias para o TMO alogênico e 60 para o autólogo). O assistente social realiza, então, nova entrevista com os familiares para averiguar as possibilidades de acomodação e permanência na cidade durante o pós-transplante imediato, período em que o paciente e o acompanhante devem permanecer na cidade, pela necessidade de internação ou de retornos ambulatoriais frequentes. Os pacientes que residem na cidade ou na vizinhança (até o máximo de uma hora de deslocamento até o

Tabela X - Acões do Serviço Social no Transplante de Medula Óssea

Fornecer orientações gerais e previdenciárias ao paciente e aos familiares

Apoiar e orientar o paciente nas suas necessidades sócio-econômicas

Auxiliar na seleção, orientação e apoio ao acompanhante do paciente

- Criar condições para o paciente e seu acompanhante permaneçam na Unidade de TMO ou próximo dela durante o período pós-transplante imediato

- Buscar recursos e criar soluções para assegurar ao paciente acesso aos medicamentos após a alta hospitalar

- Monitorizar e auxiliar a reintegração do paciente à sua comunidade de origem 
Hospital) e que disponham de condições de habitação e transporte adequados podem permanecer em suas casas após a alta hospitalar. Aos outros pacientes, o assistente social orienta quanto aos recursos de acomodação que podem ser utilizados, como pensões, hotéis, imóveis para locação, casas de familiares ou a casas de apoio a pacientes carentes (vide abaixo).

Em países mais desenvolvidos, em que os pacientes apresentam melhor nível cultural e sócio-econômico, o papel do assistente social está mais voltado ao suporte emocional do paciente e dos familiares, aproximando-se mais do trabalho desenvolvido pelo psicólogo em nosso meio ${ }^{(65)}$.

Todas essas ações são realizadas em estreito contato com outros membros da equipe multiprofissional do TMO, com os quais o assistente social se reúne frequentemente, isoladamente ou em grupo, participando também, sempre que necessário, dos encontros regulares da equipe, nas visitas médicas diárias e nas reuniões semanais do grupo de apoio psicológico à equipe (vide Capítulo VI deste Simpósio).

Paralelamente, o assistente social mobiliza recursos da comunidade a que pertence o paciente, como prefeituras, empregadores, instituições sociais e clubes de serviço, para apoiá-lo durante o procedimento e, principalmente, após a alta. Neste trabalho, busca-se conhecer também os serviços de saúde disponíveis na cidade de origem do paciente e sua situação previdenciária, orientando-o quanto à melhor maneira de utilizar esses serviços. A atuação da Assistência Social também abrange a atenção à família do paciente em relação ao suporte emocional em geral e ao auxílio para a solução de problemas sócio-econômicos que costumam acarretar muita ansiedade e interferir na cooperação com a equipe para o cuidado do paciente.

Entre outras atividades da Assistente Social ligada ao TMO estão a organização de festividades e eventos promocionais, coordenar a doação de hemoderivados pela família e pela comunidade (realizada pelo Hemocentro-RP) e as atividades da Casa de Apoio ao Transplantado de Medula Óssea- GATMO (vide abaixo).

\subsection{O Grupo de Apoio ao Transplantado de Medula Óssea (GATMO)}

As características dos pacientes encaminhados para transplante na Unidade de TMO do HCFMRP, a maioria de baixo nível sócio-econômico e provenientes de outros estados, à semelhança de outras unidades do sistema público de saúde, exigem adoção de soluções peculiares e criativas, principalmente para abrigar o paciente e seu acompanhante até ele ter condições de retornar à sua cidade de origem. No HCFMRP, toda a equipe se mobilizou, juntamente com um grupo de voluntários da comunidade, constituindose um grupo de apoio aos pacientes (GATMO), cuja missão prioritária inicial foi conseguir e adaptar uma antiga residência de professor no campus da USP para albergar os pacientes carentes e seus acompanhantes, quando não estão internados, mas precisam de ficar próximos ao hospital. Esta situação se refere, principalmente, ao período entre a primeira alta hospitalar e a época em que o paciente retorna à sua origem (D+100 para o TMO alogênico e +60 para autólogo), mas também aos retornos ambulatoriais tardios e, às vezes, até o pré-transplante.

A casa do GATMO, como é conhecida, situase a poucas quadras do HCRP, é servida por transporte gratuito provido pelo Campus da USP, é administrada em conjunto pela Assistente Social do TMO e pelo GATMO e conta com o apoio do próprio HCRP, que fornece parte da alimentação, e de outros grupos da comunidade, além do GATMO, como a Associação Brasileira de Combate ao Câncer Infantil e Adulto (ABRACCIA), clubes de serviços, lojas maçônicas, etc. Além de manterem a casa em condições impecáveis de higiene para receber os pacientes transplantados, essas entidades, coordenadas pelo GATMO e pela Assistente Social, atendem a múltiplas outras necessidades dos pacientes e familiares, incluindo medicações, alimentos especiais, transporte para a cidade de origem, sem falar no apoio emocional e orientação educacional.

Dentre 140 transplantes realizados desde que a casa do GATMO está em operação, mais de um terço dos pacientes (47) se beneficiaram de suas acomodações. Um destes pacientes, APM, 24 anos, portador de leucemia mielóide crônica em fase crônica, procedente do estado do Maranhão, chegou ao serviço acompanhado da namorada e da irmã doadora. O paciente e familiares não estavam seguros dos benefícios do transplante, tanto que a doadora retornou à sua cidade de origem logo após sua alta e não mais visitou o paciente. Sem nenhum apoio familiar, o paciente e sua acompanhante contaram apenas com a solidariedade da equipe de TMO e do GATMO, que se mobilizaram, proprocionando condições de estudo e trabalho para ambos. Mantiveram-se integrados à casa do GATMO, passando a prestar pequenos serviços a ela e realizaram seu casamento na própria casa, no início de dezembro último. Como este, vários outros pacien- 
tes tiveram o rumo de suas vidas alterados pelo TMO, não só do ponto de vista médico, mas, principalmente, porque, pela atenção recebida do GATMO e do Serviço Social, pela primeira vez em suas vidas foram tratados como cidadãos com plenos direitos de sobrevivência digna. Muitos destes pacientes, procedentes de cidades longínquas, mudaram com suas famílias e iniciaram uma nova vida na região de Ribeirão Preto, após o TMO.
Em conclusão, o trabalho de Assistência Social funciona como um elo importante entre o paciente, seus familiares e a equipe multiprofissional em todas as etapas do transplante. As ações do Serviço Social, sumarizadas na Tabela $X$, são amplas, relevantes e enriquecedoras e, quando exercidas com habilidade e sensibilidade, em parceria com outros membros da equipe e da comunidade, otimizam decisivamente o atendimento do paciente transplantado.

ANDERS JC; SOLER VM; BRANDÃO EM; VENDRAMINI EC; BERTAGNOLLI CLS; GIOVANI PG; CARVALHO EC; SUEN VM; MARCHINI JS \& VOLTARELLI JC. Nursing, nutrition, physical therapy and social work aspects of bone marrow transplantation. Medicina, Ribeirão Preto, 33: 463-485, oct./dec. 2000.

ABSTRACT: Success of bone marrow transplantation (BMT) depends upon the cooperative action of different professionals, besides the medical team, to attend complex and multiple needs of patients submitted to BMT. In this review we discuss the role of nursing, nutrition, physical therapy and social work teams in caring for those patients. The role of mental health professionals, psychologists and psychiatrists, was discussed in a separate chapter of this Symposium.

UNITERMS: Bone Marrow Transplantation.Hematopoietic Stem Cell Transplantation. Nursing. Catheterization, Central Venous. Mucositis. Nutrition. Physical Therapy. Rehabilitation. Social Work. Graft-VS Host Disease.

\section{REFERÊNCIAS BIBLIOGRÁFICAS}

1 - PASQUINI R \& FERREIRAE. Transplante de medula óssea. In: OLIVEIRA MHP. Hematologia clínica, $3^{\mathrm{a}}$ ed. Atheneu, Rio de Janeiro, Cap. 25, p.561-577, 1990.

2 - BENJAMIM S. Introduction. In: TRELEAVEN J \& WIERNIK P. Color atlas and text of bone marrow transplantation. Mosby-Wolfe, London, p.9-17, 1995.

3 - WINGARD J R. Historical perspectives and future directions. In: WHEDON MB. Bone marrow transplantation: principles, practice and nursing insights. Jones and Bartlett Publishers, Boston, Cap.1, p.3-19, 1991.

4 - FERREIRA E. Bone marrow transplantation in Brazil. Human Immunol 14:.324-332, 1985.

5 - TABAK DG. Transplante de medula. In: SCHWARTSMANN GA. Oncologia clínica: princípios e práticas. Artes Médicas, Porto Alegre, Cap.15, p.171-180, 1991.

6 - DULLEY FL. Complicações precoces no transplante de medula óssea alogênico: análise de 44 pacientes. Tese de Doutorado, Faculdade de Medicina da USP, São Paulo, p.1-134, 1992

6a - CARVALHO EC;GONÇALVES PG; BONTEMPO AP \& SOLER VM. Interpersonal needs expressed by patients during bone marrow transplantation. Cancer Nurs 23: 462-467, 2000.

7 - WOOD L; RICHARDS J \& JACOBS P. The role of the professional nurse in a bone marrow transplantation programme. Curationis 13: 77-84, 1990.
8 - TOYONAGA ET. Complicações do uso de catéteres venosos centrais de longa permanência em transplante de medula óssea. Rev Paul Enf 8:23-28,1988.

9 - BARACAT FF. Cancerologia atual - Um enfoque multidisciplinar. Roca, São Paulo, 2000.

10 - BONASSA EMA. Enfermagem em qimioterapia. Aheneu, Rio de Janeiro, 1992.

11 - ASSOCIAÇÃO PAULISTA DE ESTUDOS E CONTROLE DE INFECÇÃO HOSPITALAR. Infecção relacionada ao uso de cateteres vasculares. 1997.

12 - FONSECA SM. Manual de quimioterapia antineoplásica. Reichmann \& Affonso Editores, Rio de Janeiro, 2000

13 - KOLBINSON DA; SCHUBERT MM; FLOURNOY M \& TRUELOVE EL. Early oral changes following bone marrow transplantation. Oral Surg Oral Med Oral Pathol 66: 130-138, 1988.

14 - SANDOW PL \& BAUGHMAN RA. Dental and oral care for the head and neck cancer patient. In: MILLIOM RR \& CASSISI NJ. Management of head and neck cancer: $A$ multidisciplinary approach. $2^{\text {nd }}$ ed, JB Lippincott, Philadelphia, p. 185-191, 1994.

15 - RODRIGUEZ CS. Mucositis. In: ASH CR, ed. Cancer control a course for nurse educators. University of Florida College of Nursing, Miami, p. 119-142, 2000.

16 - SONIS ST. Mucositis as a biological process: A new hypothesis for the development of chemotherapy-induced stomatoxicity. Oral Oncol 34: 39-43, 1998. 
17 - BECK SL. Mucositis. In: JARBRO SH; FROGGE MH \& GOODMAN M, eds. Cancer symptom management. Jones and Barlett Publishers, Boston, p. 328-343, 1999.

18 - DONNELLY JP; MUUS P \& SCHATTENBERG A. A scheme for daily monitoring of oral mucositis in allogeneic BMT recipients. Bone Marrow Transplant 9: 409-413, 1992.

18a - CHARÃO MIM; SOLER NM; BONTEMPO AP \& CARVALHO EC. Avaliação da integridade oral de pacientes submetidos a transplante de medula óssea (Unidade de TMO do HCFMRP-USP). Serie de monografias da Escola Brasileira de Hematologia. XVII Congresso Nacional doColegio Brasileiro de Hematologia. Vol. 6 - Suplemento I Foz do Iguaçu - Pr. 20 a 23(10) 1999.

$18 \mathrm{~b}$ - MORRIS CW. Fundamentos da teoria dos signos. Livraria Eldorado Tijuca, Rio de Janeiro, 1976. p.1-92.

19 - BRUERA E. ABC of palliative care: anorexia, cachexia, and nutrition. BMJ 315: 1219-1222, 1997.

20 - SOUBA WW. Drug therapy: nutritional support. N Engl J Med 336: 41-48, 1997.

21 - BEARMAN SI; APPELBAUM FR; BUCKNER CD; PETERSEN FB,FISHER LD, CLIFT RA \& THOMAS ED. Regimen related toxicity in patients undergoing bone-marrow transplantation. J Clin Oncol 6: 1562-1568, 1988.

22 - MATTSSON T;ARVIDSON K; HEIMDAHL A;LYUNGMAN P; DAHLLOF G \& RINGDEN O. Alterations in taste acuity associated with allogeneic one marrow transplantation. $J$ Oral Pathol Med 21:31-37, 1992.

23 - WU D; HOCKENBERR DM; BRENTNALL TA; BAEHR PH; PONEC RJ; KUVER R; TZUNG SP; TODARO JL \& MCDONALD GB. Persistent nausea and anorexia after marrow bransplantation: a prospective study of 78 patients. Transplantation 66: 1319-1324, 1998.

24 - WINSTON DJ; HO WG \& CHAMPLIN RE. Current approaches to the management of infections in bone marrow transplants. Eur J Cancer Clin Oncol 25: S25-35, 1989. Suppl.2.

25 - WEISDORF D. Management of acute graft-versus-host disease after allogeneic bone marrow transplantation. Cancer Res Ther Control 9: 117-122, 1999.

26 - DEEG HJ; SEIDEL K; BRUEMMER B; PEPE MS \& APPELBRAUM FR. Impact of patient weight on non-relapse mortality after marrow transplantation. Bone Marrow Transplant 15:461468, 1995.

27 - MC DONALD GB; SHULMAN HM; SULLIVAN KM \& SPENCER GD. Intestinal and hepatic complications of human bone marrow transplantation. Gastroenterology 90: 460-477, 770-784, 1986.

28 - GAUVREAU-STERN JM; CHENEY CL; AKER SN \& LENSSEN $P$. Food intake patterns and food service requirements on a marrow transplant unit. J Am Diet Assoc 89: 367-372, 1989.

29 - CALDER PC \& YAQOOB P. Glutamine and the immune system. Amino Acids 17: 227-241, 1999.

30 - SCHLOERB PR \& SKIKNE BS. Oraland parenteralglutamine in bone marrow transplantation: a randomized, double-blind study. JPEN J Parenter Enteral Nutr 23: 1117-1122, 1999.

31. TOKARWS JL; COOKSON ST; MCARTHUR MA; BOYER CL; MCGEER AJ \& JARVIS WR. Prospective evaluation of rish factorsfor bloodstream infection in patients receiving home infusion therapy. Ann Intern Med 131: 340-347, 1999.
32 - STENSLAND SH \& MARGOLIS S. Simplifying the calculation of body mass index for quick reference. J Am Diet Assoc 90: 856, 1990.

33 - VANNUCCHI H; UNAMUNO MRDL\& MARCHINI JS. Avaliação do estado nutricional. Medicina, Ribeirão Preto 29: 5-18, 1996.

34 - HARRIS JA \& BENEDICT FG. A biometric study of basal metabolism in man. Camegie Institute of Washington, Washington, 1919. Publ No279.

35 - MARCHINI JS; OKANO N; CUPO P; PASSOS NMRRS; SAKAMOTO LM \& BASILE-FILHO A. Nutrição parenteral princípios gerais, formulários de prescrição e monitorização. Medicina, Ribeirão Preto 31: 62-72, 1998.

36 - FOOD AND NUTRITION BOARD NATIONAL RESEARCH COUNCIL, NAS. Recommended Dietary Allowances, 10 th ed. National Academy Press, Washington,1989.

37 - WEISDORF SA; LYSNE J; WIND D; HASHE RJ, SHARP HL, GOLDMAN A; SCHISSEL K \& MCGLAVEPB. Positive effect of prophylactic total parenteral nutrition on long-term outcome of bone marrow transplantation. Transplantation 43: 833-838, 1987.

38 - SZELUGA DJ; STUART RK; BROOKMEYER R; UTERMOHLEN $\checkmark$ \& SANTOS GW. Nutritional support of bone marrow transplant recepients: a prospective, randomized clinical trial comparing total parenteral nutrition to an enteral feeding program. Cancer Res 47: 3309-3316, 1987.

39 - SOUTAR RL \& KING DJ. Fortnightly review: bone marrow transplantation. BMJ 310: 31-36, 1995.

40 - NITENBERG G \& RAYNARD B. Nutritional support of the cancer patient: issues and dilemmas. Crit Rev Oncol Hematol 34: 137-168, 2000.

41 - JAMES MC. Physical therapy for patients after bone marrow Transplantation. Phys Ther 67:946-952, 1987.

42 - DIMEO F.; FETSCHER S.; LANGE W.; MARTELSMANN R \& KAUL J. Effects of aerobic exercise on the physical performace na incidence of $t$ reatment-related complications after high-dose chemotherapy. Blood 90:3390-3394, 1997.

43 - WINGARD JR. Functional ability and quality of life of patients after allogeneic bone marrow transplantation. Bone Marrow Transplant 14:29-33, 1994. Suppl. 4

44 - DIMEO FC; TILLMANN MHM; BERTZ H; KANZ L; MERTELSMANN R \& KEUL J. Aerobic exercise in the rehabilitation of cancer patients after figh dose chemotherapy and autologous peripheral stem cell transplantation. Cancer 79:1717-1722, 1997.

45 - DIMEO F;BERTZH.;FINKE J.;FETSCHER S.; MERTELSMANN $\mathrm{R}$ \& KEUL J. An Aerobic exercicise program for patients with haematological malignancies after bone marrow transplantation. Bone Marrow Transplant 18:1157-1160, 1996.

46 - VISSER MRM \& SMETS EMA. Fatigue, depression and quality of life in cancer patients: how are they related? Support Care Cancer 6:101-108, 1998.

47 - THUNE I. Physical exercise in rehabilitation program for cancer Patients? J Altern Complem Med 4: 205-207, 1998.

48 - HALAREM \& BEL LKR. Relação da Reabilitação com a Inatividade. IN: KOTTKE FJ \& LEHMANN JF. Tratado de medicina física e reabilitação de KRUSEN, 4 ed. Manole, São Paulo, p.1105-1124, 1994. 
49 - TUNKEL RS \& LACHMANN EA Rehabilitative medicine.In BERGER AM; PORTENOY RK \& WEISSMAN DE. Principles and practices of supportive oncology. LippincottRaven, Philadelphia, p. 681-689, 1998.

50 - DEEG HJ. Rehabilitation. In: DEEG HJ; KLINGEMANN HG; PHILLIPS GL \& VAN ZANT G. A guide to blood and bone marrow transplantantion. 3th. ed. Springer-Verlag, New York, p. 217-218, 1996.

51 - TERRA FILHO J. Avaliação laboratorial da função pulmonar. Medicina, Ribeirão Preto, 31:191-207, 1998.

52 - CRAWFORD SW; PEPE M; LIN D; BENEDETT F \& DEEG HJ. Abnormalities of pulmonary function tests after bone marrow transplantation predict nonrelapse mortality. Am J Respir Crit Care Med 152: 690-695, 1995.

53 - DEKHUIHZEN PNR; GAYAN-RAMIREZ G \& DECRAMER M. Does corticosteroid treatment affect the respiratory muscles? Eur Respir J 6:465-466, 1993.

53a -.GERBER L; HICKS H \& KLAIMAN M. Rehabilitation of the cancer patient. In: DE VITA VT; HELLMAN S \& ROSENBERG AS, eds. Cancer principles \& practice of oncology. $5^{\text {th }}$ ed. Lippincott-Raven, Philadelphia, p. 2925-2956, 1997.

54 - CHAN CK; HYLAND RH \& HUTCHEON MA. Pulmonary complications following bone marrow transplantation. Clin Chest Med 11: 323-332, 1990.

55 - SOUBANI AO; MILLER WB \& HASSOUN PM. Pulmonary complications of bone marrow transplantation. CHEST 109:1066-1077, 1996.

56 - RABITSCH W; STAUDINGER T; BRUGGER SA; REITER E; KEIL F; HEROLD C; LECHNER K; GREINIX HT \& KALHS P. Successful management of adult respiratory distress syndrome (ARDS) after high-dose chemoterapy and peripheral blood progenitor cell rescue by non-invasive ventilatory support. Bone Marrow Transplant 21:1067-1069, 1998.

57 - MEDURI H; TURNER RE; ABOU-SHALA N; WUNDERINK R \& TOLLEY E. Noninvasive positive pressure ventilation via face mask. CHEST 109: 179-193, 1996.
58 - ANTONELI M; CONTI G; ROCCO M ; BUFI M; DE BLASI RA; VIVINO G; GASPARETTO A \& MEDURI, G.U. A Comparasion of Noninvasive Positive-Pressure Ventilation and Conventional Mechanical Ventilation in Patients with Acute Respiratory Failure. N Engl J Med 339 :429-435, 1998.

59 - AZEREDO CAC. Ventilação mecânica mnvasiva e nãoinvasiva. 1.In: Ventilação mecânica domiciliar e ventilação não-invasiva. Revinter, Rio de Janeiro, p. 121-127, 1994.

60 - DECKER WA; MC GLADE JT \& FEHIR KM. Psychosocial apects and the physiological effects of a cardiopulmonary exercise Program in Patients Undergoing Bone Marrow Transplantation (BMT) for acute leuKemia (AL). Transplant Proc 21: 3068-3069, 1989.

61 - MACVICAR MG; WINNINGHAM, ML \& NICKELJL. Effects of aerobic interval training on cancer patients functional capacity. Nurs Res 38:348-351, 1989.

62 - MCARDLE WD ; KATCH FI \& KATCH VL. Fisiologia do exercício clínico para reabilitação oncológica, cardiovascular e pulmonar. In: Fisiologia do exercício. $4^{\mathrm{a}}$ ed. Guanabara Koogan, Rio de Janeiro, cap. 31, p. 637-661, 1998.

63 - BEREDJIKLIAN PK; DRUMMOND DS; DORMANS JP; DAVIDSON RS; BROCK GT \& AUGUST C. Orthopaedic manifestations of chronic Graft-Versus-Host Disease. J Ped Orthop 18: 572-575, 1998.

64 - CHAO N. Graft-Versus-Host- Disease. In: BURT K.; DEEG HJ.; LOTHIAN ST \& SANTOS GW. Bone marrow transplantation. R. G. LANDES Company, Austin, p. 478-497, 1998.

65 - CWIKEL JG \& BEHAR LC. Social work with adult cancer patients: a vote-count review of intervention research. Soc Work Health Care 29: 39-67, 1999.

Recebido para publicação em 25/10/2000

Aprovado para publicação em 20/12/2000 